\title{
Measuring Criticality of Raw Materials: An Empirical Approach Assessing the Supply Risk Dimension of Commodity Criticality
}

\author{
Herbert Mayer, Benedikt Gleich \\ Institute for Materials Resource Management, University of Augsburg, Augsburg, Germany \\ Email: herbert.mayer@mrm.uni-augsburg.de, benedikt.gleich@mrm.uni-augsburg.de
}

Received 6 January 2015; accepted 25 January 2015; published 28 January 2015

Copyright (C) 2015 by authors and Scientific Research Publishing Inc.

This work is licensed under the Creative Commons Attribution International License (CC BY). http://creativecommons.org/licenses/by/4.0/

(c) (i) Open Access

\begin{abstract}
Providing a sustainable and reliable supply of raw materials at economic prices has become essential to industrialized economies. Therefore, the need for both economical and sustainable methods and strategies for the management of raw materials has been postulated to enable companies and economies to counteract dramatic effects of supply disruptions, or at least to provide early warnings. The relevant studies assign generic weights to different driving factors and therefrom derive criticality indexes. However, it often remains open how to interpret the resulting measures and how to apply them practically. Here we show that based on current commodity key figures, it is possible to empirically determine the risk for future price increases and fluctuations. Thus, we can identify future supply risks and incorporate their patterns into an empirically calibrated criticality measurement. To this end, we apply the well-known compounding framework used by many companies for their financial planning, calculating net present values and volatility from the predicted future price development. To calibrate each resource specific model, we perform extended regression analyses on our compounded criticality index from time series of 42 (out of about 60 industrially relevant) chemical elements. The analysis thereby covers 9 driving factors for criticality and a 40-year time span. Our results suggest a fundamental modification of current practices for criticality assessment, in particular by scaling the criticality measure to correspond with the net present value of future commodity expenses and future volatility.
\end{abstract}

\section{Keywords}

Raw Materials, Criticality Assessment, Commodity Criticality, Criticality Index

\section{Introduction}

In the recent past, the rise of emerging economies has led to a significantly increased demand for raw materials. China, in the last decade, has grown to be the world's largest consumer of metals. Chinese industry accounted 
for approximately $36 \%$ of the 22.1 million tons of used copper worldwide [1]. Raw material supply, on the other hand, is rather inflexible, as capacity expansions in most cases are coupled with high investments and duration of new mining projects rarely remains less than five years. At the same time, new life-styles, population growth, technological change and protectionist governance contribute to changing dynamics in the commodity market. Due to these developments, raw material availability in many cases is increasingly under pressure. We could observe immense price increases and unprecedented magnitudes of price fluctuations that reached a level which was unimaginable even a few years ago. However, raw materials are essential for an efficient functioning of industrialized economies. Being indispensable for nearly all main industry sectors - aeronautic, automotive, chemical, new energy, engineering or health care - the massive impacts of potential restrictions in long-term supply on economic systems and on their actors are quite inconceivable. Providing a sustainable and reliable supply of raw materials at competitive prices, therefore, has become essential, as many manufacturing companies are struggling with the implications of this development. Managers have to deal with growing uncertainty in material planning, breaks in production or the financial stress arising from the increasing volatility. Enterprises are rarely able to pass down the rising number of price increases. More and more companies and governmental agencies fear future supply risks and the economical impact of the changing conditions [2] [3]. In addition, decisionmakers today have to keep up with difficult and complex markets not for one or two, but rather for a dozen of metals under very heterogeneous conditions.

To cope with these risks, considerable need for action for both economical and sustainable methods and strategies for the management of raw materials has been postulated to enable companies and economies to at least partly counteract the dramatic effects of potential physical supply disruptions, market imbalances or demand explosions [4]-[6].

Therefore, the concept of commodity criticality indexes, providing an aggregated estimate of the overall "criticality"1 of raw materials, capturing the supply risks and the vulnerability of a system [7], has been developed, to support the decision-making process and to simplify the development of long term commodity utilization strategies [4]. In fact, there are a number of approaches by now to determine the criticality of raw materials. [7] summarizes the current state of research and gives a review of the major concepts, which to a large extent differ substantially. For instance, [8] from the USA Department of Energy applies a fixed weighting scheme for five criticality indicators. [6], focusing on the supply dimension, develops a criticality assessment aggregating five indicator variables graphically by using a radar chart. [5], using a pragmatic approach, basically aggregates supply risks and economic importance. A quite new approach presented by [9] assesses raw material criticality within a comprehensive framework considering, supply risk, environmental implications and vulnerability as three dimensions. In addition, there is a variety of other industry pragmatic and company-specific approaches, which for a large part are based on personal assessments or weighted average of applied indicators.

Since it is still a new and complex subject of research, there is no unequivocal methodology to identify critical materials. Starting from rather qualitative analyses, current approaches as yet consist of rather arbitrary, not validated aggregations based on fixed percentages or other static aggregates, which are applied to all investigated commodities. What is more, almost all presented methods use different aggregates. In [10], this issue is explicitly addressed - to our knowledge - for the first time. Therefore, this work inspires and serves as basis of the current study. Besides the reliability of these approaches, it in particular remains unclear how to interpret and how to apply them practically. In effect, especially companies, which face the challenge of hedging against volatile commodity markets and supply risks, may use the current measures in a misleading way or are completely unaware on how to use them properly. To shed some more light on this issue, we intend to answer how the methodical procedure of measuring criticality of mineral resources can be improved, while enhancing usability for industrial application. Therefore, focusing on the supply risk dimension of criticality, we present a statistical assessment framework for identifying supply risk patterns to make forecasts about future material price development and volatility. Thereby, we want to facilitate companies and governments to be aware of upcoming critical market developments and to counteract them. Facilitating practical usability, the measurement is based on the well-established compounding framework.

While this section presents an introduction, the subsequent section outlines the relevant literature and specifies the problem context. To address the research question, we present a supply risk assessment framework and proceedings of intense evaluation methods in the methodological section. Then we present the empirical results

${ }^{1}$ To define a raw material as critical, it must face high risks with regard to access to it, i.e. high supply risks or high environmental risks, and be of high economic importance [5]. 
of the supply risk assessment. In the fifth section, the results are discussed and interpreted. Finally, the work concludes with a summary and starting points for further research.

\section{Current State of Research}

The concept of criticality in terms of raw materials appeared for the first time in 1939. With the so called Material Stock Piling Act, the USA Government regulated the securing of militarily relevant materials for which availability had become uncertain due to geopolitical developments [2]. Nevertheless, little research has been done up to the beginning of the last decade, since when this topic nearly emerges. Hence, analysis and evaluation of the criticality in this context is still a young and heterogeneous topic. Intensive research on criticality of raw materials has been conducted only within in the last years.

\subsection{Literature Review}

The high relevance of resource criticality is demonstrated by several well-known and frequently discussed studies, for instance [9] and [11]-[16]. But even though many studies are working intensively on this subject and tend to converge in a way, they in most cases consider criticality from each individual point of view. So far, there is no clear definition of criticality of raw materials. Nevertheless, all studies have in common that they consider raw material criticality a relative concept. Materials are labelled critical if their relevance to economic systems and threats for future supply restrictions are higher compared to other materials [2] [5] [17]. Going into more detail, criticality also depends on the perspective. In contrast to the more widespread economic perspective, [6] coming from an industrial point of view, present a method of assessing criticality in form of long-term supply risks for individual mineral raw materials. In the same category, [18] on behalf of General Electric (GE) identify critical materials at risk of supply constraints as well as price increases. Only these few excerpts show the heterogeneity of this topic.

To summarize, [7] with one of the major works in current research, contribute a literature overview of the broad concept of raw material criticality, and thereof deduce a general definition. According to them, resource criticality captures two dimensions: the supply risk and the vulnerability of a system to potential supply disruptions. This rather abstract definition is certainly hard to operationalize. As previously mentioned, there are even studies taking into account a third dimension: environmental risk or implications [5] [9].

To take a closer look at the varying approaches assessing the criticality, Table 1 shows an overview and characteristics of major criticality studies. Criticality as a whole in most cases is a rather specific subject, as it strongly depends on the point of view from which it is conducted and on the purpose of use. Criticality studies consequently show different scopes and perspectives, e.g. from a national economy, a company or a functional view on specific materials. The main dimensions in most cases are vulnerability in terms of importance of use or impact of supply disruptions and supply risk, e.g. demand trends, mine production, or producer concentration. Different perspectives imply the usage of various indicators. But in addition, the main indicators show little accordance among the diverse approaches, even when conducted from the same perspective. Some driving factors even appear in both dimensions, as for instance substitutability. A closer look reveals that the factors mainly associated with the vulnerability dimension, like strategic relevance, impact of disruptions or the ability to pass through price increases to consumers, are more of a qualitative nature, whereas the supply risk dimension indicators, e.g. producer concentration, mine production or consumption are mainly quantitative measures. Figure 1 summarizes the characteristics of these criteria. Aggregating these indicators, equal or indicator-specific weights are used in most cases. Moreover, almost all studies use a general model for all materials to be analyzed. Considering the final assessment different ways of representation can be observed: graphical aggregation, matrices and indexes as well as future market situation analysis. Often, the scale of measure is an ordinal scale, which merely offers rank-ordering. In addition, while identifying and assessing long-term supply risk, many studies use projections of future supply and demand trends [6] [8] [18]-[20].

\subsection{Research Question}

Altogether, these studies help strengthening the understanding of minerals criticality and make a decisive contribution to improve the assessment of the mineral commodity markets and future developments. But there is still plenty of room for enhancement and research. In the current state of research, the aggregation and especially 
Table 1. Overview and characteristics of frequent discussed criticality studies $(\mathrm{SR}=$ Supply risk; VU = Vulnerability; ER = Environmental risk).

\begin{tabular}{|c|c|c|c|c|c|}
\hline & $\begin{array}{l}\text { Focus and } \\
\text { Perspective }\end{array}$ & $\begin{array}{c}\text { Main } \\
\text { Dimensions }\end{array}$ & $\begin{array}{l}\text { Main Indicators } \\
\left(\mathbf{V U} * / \mathbf{S R}^{*} / \mathbf{E R}^{*}\right)\end{array}$ & Weighting & $\begin{array}{l}\text { Aggregation } \\
\text { and Scale }\end{array}$ \\
\hline $\begin{array}{l}\text { Frondel et al. } \\
\text { (2007) Trends in } \\
\text { Supply and Demand } \\
\text { for Mineral Raw } \\
\text { Materials }\end{array}$ & $\begin{array}{l}\text { Assessing } \\
\text { long-term } \\
\text { supply and } \\
\text { demand, } \\
\text { economy }\end{array}$ & $\begin{array}{l}\text { Development of } \\
\text { supply/and } \\
\text { demand }\end{array}$ & $\begin{array}{c}\text { VU: -/SR: Trend of mine } \\
\text { production/Secondary Production } \\
\text { development/Demand trend/Technology } \\
\text { development forecast }\end{array}$ & $\begin{array}{l}\text { No } \\
\text { aggregation } \\
\text { and } \\
\text { weighting }\end{array}$ & $\begin{array}{c}\text { Scenario } \\
\text { analysis of } \\
\text { supply and } \\
\text { demand } \\
\text { developments, } \\
\text { implications }\end{array}$ \\
\hline $\begin{array}{c}\text { Morley and } \\
\text { Eatherley (2008) } \\
\text { Material Security: } \\
\text { Ensuring Resource } \\
\text { Availability for the } \\
\text { UK Economy }\end{array}$ & $\begin{array}{l}\text { Identifying } \\
\text { insecure } \\
\text { materials, } \\
\text { economy }\end{array}$ & $\begin{array}{c}\text { Material } \\
\text { risk/Supply risk }\end{array}$ & $\begin{array}{c}\text { VU: Global } \\
\text { consumption/Substitutability/Global } \\
\text { warming potential/Production effort SR: } \\
\text { Ratio of reserves/Supply } \\
\text { concenration/Political stability }\end{array}$ & $\begin{array}{l}\text { Indicators } \\
\text { equally } \\
\text { weighted and } \\
\text { aggregated }\end{array}$ & $\begin{array}{l}\text { Criticality } \\
\text { index/Ordinal } \\
\text { Scale }\end{array}$ \\
\hline $\begin{array}{l}\text { Pfleger et al. (2009) } \\
\text { Rohstoffsituation } \\
\text { Bayern: Keine } \\
\text { Zukunft ohne } \\
\text { Rohstoffe }\end{array}$ & $\begin{array}{l}\text { Identifying of } \\
\text { vulnerabilities } \\
\text { and materials } \\
\text { supply risk }\end{array}$ & $\begin{array}{l}\text { Quantitative } \\
\text { indicators/ } \\
\text { Qualitative } \\
\text { indicators }\end{array}$ & $\begin{array}{l}\text { VU: Techology relevance/Strategic } \\
\text { relevance/Substitutabilty SR: Static } \\
\text { reserves/Coutry risk/Country \& Company } \\
\text { concentration/Price risk }\end{array}$ & $\begin{array}{l}\text { Indicators } \\
\text { unequally } \\
\text { weighted }\end{array}$ & $\begin{array}{l}\text { Criticality } \\
\text { index/Ordinal } \\
\text { scale }\end{array}$ \\
\hline $\begin{array}{l}\text { Rosenau-Tornow et } \\
\text { al. (2009) Assessing } \\
\text { the Long-Term } \\
\text { Supply Risks for } \\
\text { Mineral Raw } \\
\text { Materials }\end{array}$ & $\begin{array}{l}\text { Indentifying } \\
\text { and assessing } \\
\text { future supply } \\
\text { risks for raw } \\
\text { materials, } \\
\text { company }\end{array}$ & -/Supply risk & $\begin{array}{c}\text { VU: -/SR } \\
\text { Production/stocks/consumption)/Production } \\
\text { costs/Country stability/Concentration of } \\
\text { producers/Future market trends }\end{array}$ & $\begin{array}{l}\text { Individual } \\
\text { calculation of } \\
\text { indicators, } \\
\text { equally } \\
\text { weighted }\end{array}$ & $\begin{array}{l}\text { Risk profil } \\
\text { using a spider } \\
\text { web diagramm, } \\
\text { Nominal scale }\end{array}$ \\
\hline $\begin{array}{l}\text { Duclos et al. } \\
\text { (2010) Design in an } \\
\text { Era of Constrained } \\
\text { Resources }\end{array}$ & $\begin{array}{l}\text { Identifying the } \\
\text { materials at risk } \\
\text { of supply } \\
\text { constraints or } \\
\text { price increases, } \\
\text { company }\end{array}$ & $\begin{array}{l}\text { Impact on } \\
\text { company/Supply } \\
\text { and price risk }\end{array}$ & $\begin{array}{c}\text { VU: Share of world } \\
\text { supply/Substitutability/Ability to pass } \\
\text { through price increases SR: } \\
\text { Abundance/Future Demand/Historic price } \\
\text { volatility/Supply Concentration }\end{array}$ & $\begin{array}{l}\text { Indicators } \\
\text { equally } \\
\text { weighted }\end{array}$ & $\begin{array}{l}\text { Criticality ma- } \\
\text { trix/Ordinal } \\
\text { scale }\end{array}$ \\
\hline $\begin{array}{l}\text { EU (2010) Critical } \\
\text { Raw Materials for } \\
\text { the EU }\end{array}$ & $\begin{array}{l}\text { Indentifying } \\
\text { critical raw } \\
\text { materials, EU } \\
\text { economy }\end{array}$ & $\begin{array}{l}\text { Economic } \\
\text { importance/ } \\
\text { Supply } \\
\text { risk/Environment } \\
\text { al risk }\end{array}$ & $\begin{array}{c}\text { VU: Share value of end use/SR: Supply } \\
\text { concentration } \\
\text { and stability/Substitutability/Secondary } \\
\text { production ER: } \\
\text { Environmental performance }\end{array}$ & $\begin{array}{l}\text { Individual } \\
\text { calculation of } \\
\text { indicators, } \\
\text { equally } \\
\text { weighted }\end{array}$ & $\begin{array}{l}\text { Criticality } \\
\text { matrix/Ordinal } \\
\text { scale }\end{array}$ \\
\hline $\begin{array}{l}\text { Behrendt et al. } \\
\text { (2011) Kritische } \\
\text { Rohstoffe für } \\
\text { Deutschland }\end{array}$ & $\begin{array}{l}\text { Identifying of } \\
\text { important } \\
\text { economic } \\
\text { materials and } \\
\text { future supply } \\
\text { risks, economy }\end{array}$ & $\begin{array}{c}\text { Impact on } \\
\text { German } \\
\text { economy/Supply } \\
\text { risk }\end{array}$ & $\begin{array}{l}\text { VU: Quantity and strategic } \\
\text { relevance/Substitutability/SR:Country } \\
\text { risk/Market risk/Structure risk }\end{array}$ & $\begin{array}{l}\text { Indicators } \\
\text { unequally } \\
\text { weighted }\end{array}$ & $\begin{array}{l}\text { Criticality } \\
\text { matrix/Ordinal } \\
\text { scale }\end{array}$ \\
\hline $\begin{array}{l}\text { Graedel et al. } \\
(2012) \\
\text { Methodology of } \\
\text { Criticality } \\
\text { Determination }\end{array}$ & $\begin{array}{l}\text { Quantifying } \\
\text { degree of } \\
\text { criticality of the } \\
\text { metals of the } \\
\text { periodic table, } \\
\text { variable }\end{array}$ & $\begin{array}{l}\text { Vulnerability to } \\
\text { supply } \\
\text { disruption/Supply } \\
\text { risk/Environment } \\
\text { al implications }\end{array}$ & $\begin{array}{c}\text { VU: Perspective depending } \\
\text { impact/Strategic } \\
\text { relevance/Substitutability/Innovation/SR: } \\
\text { Depletion time/Policy } \\
\text { Potential/HDI/Political Stability/Supply } \\
\text { concentration ER: Damage potential }\end{array}$ & $\begin{array}{l}\text { Individual } \\
\text { and flexible } \\
\text { aggregation, } \\
\text { unequally } \\
\text { weighted }\end{array}$ & $\begin{array}{l}\text { 3-dimensional } \\
\text { criticality matrix } \\
\text { and criticality } \\
\text { index/Ordinal } \\
\text { scale }\end{array}$ \\
\hline
\end{tabular}




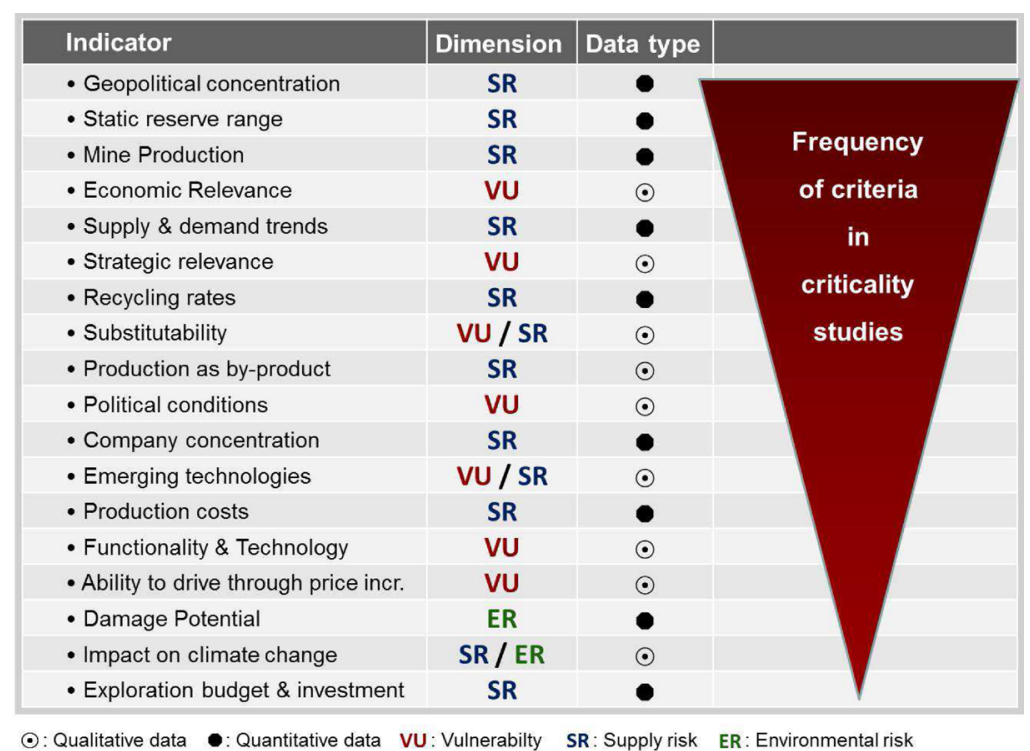

Figure 1. Overview and characteristics of criticality criteria ordered by frequency (Source: Own representation based on [10]).

the weighting of different indicators is compiled individually and rather arbitrarily, as there is hardly any unequivocal methodology so far. [7] states the weighting methods to be subjective and pragmatic, since they are largely unexplained. According to [5], "determining criticality [...] is not a matter of exact science yet and it is subject to various methodological challenges. Central questions relate to data availability and how the different indicators should be aggregated and combined". [10], for the first time, addresses the topic by an empirical approach, but initially concentrate on the economic scarcity of materials. Thus, this study inspires the authors and serves as basis of the further development and more advanced approach, presented in this work. Moreover, the fact that there are no individual models taking into account a metal's specific characteristics is not yet addressed by current studies. Since arbitrariness should be avoided whenever possible, a more empirical quantitative approach seems highly desirable for the future.

Another important question for companies that has not yet been under study is the interpretation of the resulting measures and their practical application. Companies seek for usable methods and tools to get awareness and to be, at least partly, able to counteract upcoming critical market developments.

To summarize, two important issues which have not yet been sufficiently addressed by current research are: 1) resource specific models and 2) practical implications for companies. Therefore, in this study we address the improvement of the methodology of criticality assessment of raw materials, while ensuring resource specific models and an enhanced practical application.

When it comes to implementation, we refer to [10] [21] [22] who proclaim the commodity market price to be the most "readily available and reliable" measure for future resource availability, as the price is a result of the equilibrium of demand and supply. According to this quite plausible thesis, prices reflect costs of alternative terms and goods that must be forgone in order to obtain a mineral commodity. As stated above, many studies use projections of future supply and demand trends to assess future supply risk and thus future availability trends. Addressing this issue, we analyze the instrument of the future price as indicator for future availability development. Our empirical and statistical approach according to [6] and [23] focuses on the supply risk dimension for two reasons. This kind of risk to a system belongs to the external risks [18] and therefore is not depending on the examined subject. Secondly, the supply risk indicators are of a quantitative nature which enables a formal aggregation of indicators to measure criticality, and hence, future availability.

\section{Methodology}

We present an empirical methodology of assessing supply risks of minerals criticality in form of future price development and volatility. Therefore, at first we present the extensive dataset in the following sub-section. 
Then, the necessary data processing is explained before we introduce our empirical assessment approach in detail, which is based on the well-known capital value and continuous compounding framework. To calibrate resource specific models and assess potential correlations we use classical linear regression analysis.

\subsection{Data and Processing}

For the presented criticality assessment we use the extensive data set of [10], based on USA Geological Survey (USGS) and Raw Materials Group data (RMG, now SNL Metals \& Mining). In addition, we extended this data set by 14 more years to enhance consistency and validity. Thus, the presented analysis is based on historical time series data of 41 years from 1970 to 2010 . Currently, this is the maximum time frame that offers broad data availability and allows a consistent data set for the examined set of indicators. A broad selection of industrially used materials provides a wide overview how the nine considered factors influence potential resource supply risk. Yearly average prices serve as basis for price trend and future volatility calculation. All metal prices are measured in USA dollars per metric ton and originate from USGS. Table 2 shows an overview of the analyzed elements and their characteristics. Representing 42 out of roughly 60 industrially relevant raw materials, it includes the economically most important elements and offers a broad and extensive data basis. Figure 2 shows a classification of the examined elements within the periodic table.

Thereby materials represent all levels of price, supply and consumption. When it comes to the selection of potential indicators for resource supply risk development, which is determined by future price and volatility trend, we again refer to the previous work of [10]. Indicators, following [24] or [20] from both, supply and demand perspective are included. With focus on a methodological improvement of assessing and aggregating

Table 2. Overview of examined raw materials and characteristics.

\begin{tabular}{|c|c|c|c|c|c|c|c|c|c|}
\hline Element & Abr. & $\begin{array}{l}\text { Atomic } \\
\text { No. }\end{array}$ & $\begin{array}{l}\text { Atomic } \\
\text { Mass (u) }\end{array}$ & $\begin{array}{l}\text { Density } \\
\left(\mathrm{kg} / \mathrm{m}^{3}\right)\end{array}$ & Element & Abr. & $\begin{array}{l}\text { Atomic } \\
\text { No. }\end{array}$ & $\begin{array}{l}\text { Atomic } \\
\text { Mass (u) }\end{array}$ & $\begin{array}{l}\text { Density } \\
\left(\mathrm{kg} / \mathrm{m}^{3}\right)\end{array}$ \\
\hline Aluminium & $\mathrm{Al}$ & 13 & 26.98 & 2700 & Mercury & $\mathrm{Hg}$ & 80 & 200.59 & 13,550 \\
\hline Antimony & $\mathrm{Sb}$ & 51 & 121.75 & 6690 & Molybdenum & Mo & 42 & 95.94 & 10,280 \\
\hline Arsenic & As & 33 & 74.92 & 5720 & Nickel & $\mathrm{Ni}$ & 28 & 58.69 & 8910 \\
\hline Beryllium & $\mathrm{Be}$ & 4 & 9.01 & 1850 & Palladium & $\mathrm{Pd}$ & 46 & 106.42 & 12,020 \\
\hline Bismuth & $\mathrm{Bi}$ & 83 & 208.98 & 9800 & Phosphorus & $\mathrm{P}$ & 15 & 30.97 & 1820 \\
\hline Boron & B & 5 & 10.81 & 2460 & Platinum & $\mathrm{Pt}$ & 78 & 195.08 & 21,450 \\
\hline Bromine & $\mathrm{Br}$ & 35 & 79.9 & 3140 & Potassium & K & 19 & 39.1 & 860 \\
\hline Cadmium & $\mathrm{Cd}$ & 48 & 112.41 & 8640 & Rhenium & $\mathrm{Re}$ & 75 & 186.21 & 21,030 \\
\hline Chromium & $\mathrm{Cr}$ & 24 & 52 & 7140 & Rhodium & $\mathrm{Rh}$ & 45 & 102.91 & 12,410 \\
\hline Cobalt & $\mathrm{Co}$ & 27 & 58.93 & 8890 & Silicon & $\mathrm{Si}$ & 14 & 28.09 & 2330 \\
\hline Copper & $\mathrm{Cu}$ & 29 & 63.55 & 8920 & Silver & $\mathrm{Ag}$ & 47 & 107.87 & 10,490 \\
\hline Gallium & $\mathrm{Ga}$ & 31 & 69.72 & 5910 & Sodium & $\mathrm{Na}$ & 11 & 22.99 & 970 \\
\hline Germanium & $\mathrm{Ge}$ & 32 & 72.61 & 5320 & Strontium & $\mathrm{Sr}$ & 38 & 87.62 & 2630 \\
\hline Gold & $\mathrm{Au}$ & 79 & 196.97 & 19,320 & Sulfur & $\mathrm{S}$ & 16 & 32.07 & 2060 \\
\hline Indium & In & 49 & 114.82 & 7310 & Tantal & $\mathrm{Ta}$ & 73 & 180.95 & 16,680 \\
\hline Iodine & I & 53 & 126.9 & 4940 & Tin & $\mathrm{Sn}$ & 50 & 118.71 & 7290 \\
\hline Iron & $\mathrm{Fe}$ & 26 & 55.85 & 7870 & Titanium & $\mathrm{Ti}$ & 22 & 47.88 & 4510 \\
\hline Lead & $\mathrm{Pb}$ & 82 & 207.2 & 11,340 & Tungsten & W & 74 & 183.85 & 19,260 \\
\hline Lithium & $\mathrm{Li}$ & 3 & 6.94 & 530 & Vanadium & V & 23 & 50.94 & 6090 \\
\hline Magnesium & $\mathrm{Mg}$ & 12 & 24.3 & 1740 & Zinc & $\mathrm{Zn}$ & 30 & 65.39 & 7140 \\
\hline Manganese & $\mathrm{Mn}$ & 25 & 54.9 & 7440 & Zirconium & $\mathrm{Zr}$ & 40 & 91.22 & 6510 \\
\hline
\end{tabular}




\section{Periodic table}

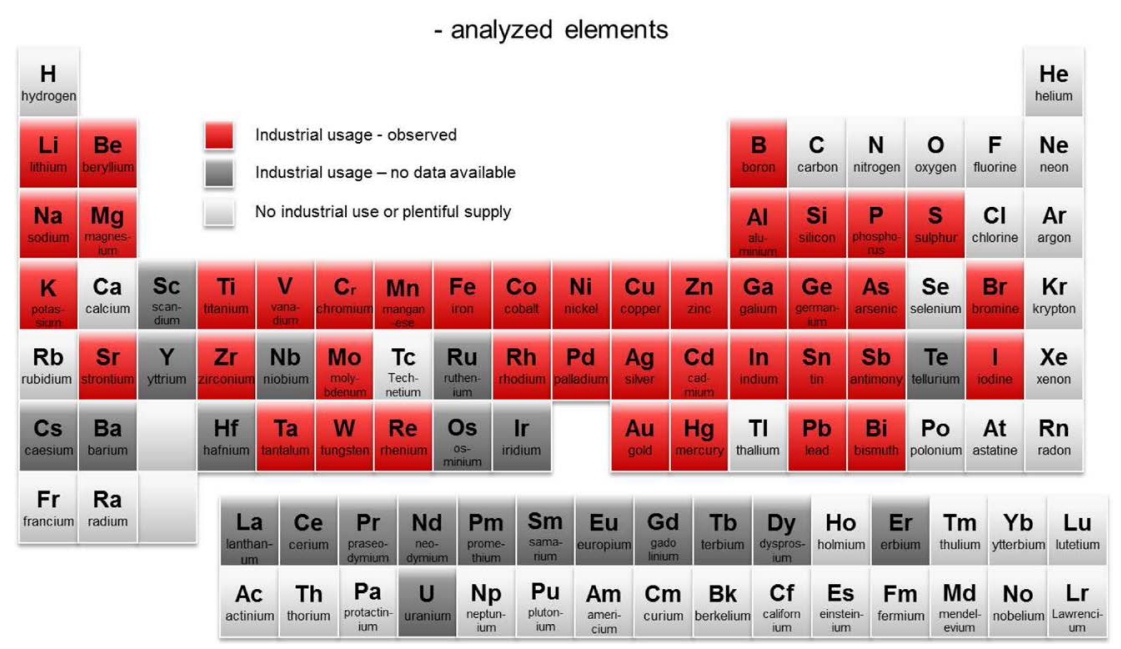

Figure 2. Graphical representation of a periodic table showing the analyzed elements (The elements marked red are addressed by this study. For grey elements no information was available. Both red and grey highlighted elements are of industrial relevance. White elements are either not used in industrial applications or abundant; Source: Representation based on [10]).

supply risk criticality, resource specific criteria are also selected according to their frequency of use in current criticality assessment studies, as well as the required quantitative data type (see Figure 1). Regarding economic factors seeming to intensely drive demand of raw materials, the most important and generally accepted were taken into account, see Table 4.

According to the classical theory of economics, supply and demand determine the price development; therefore, our analysis includes major components from both dimensions. Table 3 shows a detailed overview of the resource specific variables. As, the factors are mostly identical to the ones of [10], we keep explanation short and refer to their work for more detailed description and explanations. Thereby, the following five material specific indicators-world mine production, USA consumption, secondary production, stocks and country concentration are included in the analysis, as they are attributed to cause supply risks and significantly influence price and volatility development.

Important economic factors are neglected in many studies, although it can hardly be denied that they strongly influence commodity markets. GDP (gross domestic product) without doubt is one of the most important representatives for economic growth and thus for demand for (non-renewable) resources. Another important factor, which has to be considered in context of price development is inflation [25]. An alternative, quite widespread, important factor, which can be traced back to [26], is the rate of interest. This idea has been also supported and pursued by [27]. Lastly, we include one additional indicator: Since commodity derivatives - such as futures, forwards or options - are contractual agreements about future purchase and sale of particular commodities at a determined price, we want to analyze whether futures can offer information about supply risks, and hence, on price trends and volatility. The economic indicators originate from the World Bank (World Development Indicators), the International Monetary Fund (IMF) and Futures Data. Table 4 gives an overview of the examined economic factors: In all tables in the reminder of the paper, commodity as well as indicator shortcuts are used.

Table 5 and Table 6 give a brief overview of statistical key figures of data samples, presenting the mean and the standard deviation of the respective variable for each resource.

As suggested in [10], to deal with some inconsistencies, minor data gaps and the requirements of our calibration method, we apply appropriated and necessary adjustments. To ensure scale invariance (characteristic feature of factors not changing by transformation), prices and the world gross domestic product are converted to a logarithmic scale. Due to the, for a large part, exponential increase of GDP, the logarithmic scale enables compatibility with a linear regression model. To bypass missing values, we apply mean substitution and case deletion (list-wise). 
Table 3. Overview of the resource specific factors (source: own representation based on [10]).

\begin{tabular}{|c|c|c|c|c|c|}
\hline Indicator & Country Concentration & World Mine Production & Apparent Consumption & Secondary Production & Stocks \\
\hline Shortcut & HHI_Country & MineProd & App Consum & X2Prod & Stocks \\
\hline Measure & HHI & {$[\mathrm{t}]$} & {$[\mathrm{t}]$} & {$[\mathrm{t}]$} & {$[\mathrm{t}]$} \\
\hline Geographic focus & Global & Global & USA & USA & USA \\
\hline Data source & $\begin{array}{l}\text { Raw Material Group, } \\
2012\end{array}$ & USGS, 2012 & USGS, 2012 & USGS, 2012 & $\begin{array}{l}\text { USGS, } \\
2012\end{array}$ \\
\hline
\end{tabular}

Table 4. Overview of the economic and demographic factors (source: own representation based on [10]).

\begin{tabular}{|c|c|c|c|c|}
\hline Indicator & Real Interest Rate & Logarithmic World GDP & Inflation Rate & Futures \\
\hline Shortcut & Interest & LN_GDP & US_Infla & Future 6 \\
\hline Measure & Annual in \% & Billion \$ & Annual in $\%$ & Settle prices in $\$, 6 \mathrm{~m}$ \\
\hline Geographic focus & USA & Global & USA & USA \\
\hline Data source & WDI, Word Bank, 2012 & IMF, 2011 & WDI, World Bank, 2012 & Futures Data, 2012 \\
\hline
\end{tabular}

\subsection{Empirical Framework Assessing Supply Risks}

To identify potential supply risks we use a set of methods well-established in finance which include practiceoriented assessment techniques. As stated above, many studies use projections of future supply and demand trends to assess future supply risk, thus availability trends. Besides, as described in detail in section 0, [21] [22] establish the commodity price as a measure for resource availability. We combine these statements and use the instrument of future price development and volatility as measures for future availability development. To avoid point estimates which usually come along with a high probability of not matching with the true parameter value, we create a supply risk measure that is based on two components. On the one hand, based on established financial measures, we determine future price trends. And on the other hand, since not only price trends are indicating future availability situations, but also future fluctuations, we include future volatility as a second measure.

In the first step defining a price trend aggregate, we use the fundamental concept of the net present value (NPV), which is defined as the sum of the present values (PV) in the respective time frame. This form of calculation is widely used in business and economics to provide a means to compare cash flows or prices at different points in time, taking inflation and returns into account. As common in financial computations, we use the compounding framework in its continuous form. The initial formula of the present value, adopted to the raw materials price context, is:

$$
p_{p v}=p_{t} \cdot \mathrm{e}^{-r t}
$$

where $p_{p v}$ is the present value, $p_{t}$ denotes the price at a future time $t$ and $r$ marks the discount rate. In practical application companies use an effective interest rate $r$ as a valuation interest rate to make payments at various points of time valuable. To state a value for price development now and to make it comparable among diverse commodities, we use inflation rate as valuation rate $r$ and standardize the present value $p_{p v}$ by the actual value of a material at the current point of time $p_{0}$. This, for instance, enables the calculation of the relative deviation from a material price to inflation at two different points in time. The corresponding formula is:

$$
\widehat{\mathrm{PDI}}_{t}=\frac{p_{p v}}{p_{0}}=\frac{p_{t} \cdot \mathrm{e}^{-r t}}{p_{0}}
$$

Thus we formed a normalized indicator for price development $\widehat{\mathrm{PDI}}_{t}$. This implicates, that specific values of price development $\widehat{\mathrm{PDI}}_{t}>1$, signal real price increases above inflation, values of $\widehat{\mathrm{PDI}}_{t}=1$ an increase along inflation (no increase in real prices), and finally a value of $\widehat{\mathrm{PDI}}_{t}<1$ indicates a decrease of real prices.

Thus far, we only have considered one future point in time. Now expanding the observation period, which implies additional points in time $p_{0}, p_{1}, p_{2}, \cdots, p_{n}$, we sum up the respective values of $\mathrm{PDI}_{t}$ and normalize it by the degree of observation dates, which is $n+1$ including $p_{0}$, illustrated by Figure 3 . The corresponding formula is 
Table 5. Descriptive statistics-resource specific factors.

\begin{tabular}{|c|c|c|c|c|c|c|c|c|c|c|c|c|c|c|}
\hline \multirow[b]{2}{*}{ Com } & \multicolumn{2}{|c|}{ Price } & \multicolumn{2}{|c|}{ HHI_Country } & \multicolumn{2}{|c|}{ MineProd } & \multicolumn{2}{|c|}{ AppConsum } & \multicolumn{2}{|c|}{ 2Prod } & \multicolumn{2}{|c|}{ Stocks } & \multicolumn{2}{|c|}{ future6 } \\
\hline & Mean & Std & Mean & Std & Mean & Std & Mean & Std & Mean & Std & Mean & Std & Mean & Std \\
\hline $\mathrm{Al}$ & 1487 & 549 & 0.100 & 0.021 & $20,520,732$ & $8,402,165$ & $5,169,268$ & 956,097 & $2,368,537$ & 946,366 & 2249024.39 & 545173.39 & & \\
\hline As & 728 & 282 & & & 39,534 & 11,395 & 16,995 & 6784 & & & 2644.27 & 2301.59 & & \\
\hline $\mathrm{B}$ & 669 & 252 & 0.301 & 0.070 & $3,016,561$ & $1,429,975$ & 432,722 & 85,684 & & & & & & \\
\hline $\mathrm{Be}$ & 416,390 & 245,778 & & & 224 & 92 & 226 & 95 & & & 120.24 & 65.49 & & \\
\hline $\mathrm{Bi}$ & 10,566 & 5970 & & & 4400 & 1348 & 1432 & 506 & & & 249.63 & 100.65 & & \\
\hline $\mathrm{Br}$ & 795 & 412 & & & 403,683 & 106,743 & 189,946 & 40,464 & & & & & & \\
\hline $\mathrm{Cd}$ & 4413 & 3346 & & & 18,917 & 1726 & 2968 & 1598 & & & 818.02 & 606.48 & & \\
\hline $\mathrm{Cr}$ & 930 & 652 & 0.235 & 0.021 & $3,823,659$ & $1,481,872$ & 542,268 & 115,645 & 169,634 & 22,188 & 141540.24 & 131389.80 & & \\
\hline $\mathrm{Cu}$ & 2560 & 1738 & 0.125 & 0.023 & $10,111,220$ & $3,230,708$ & $2,275,610$ & 382,172 & 405,951 & 143,908 & 360304.88 & 232822.97 & 1.13 & 0.84 \\
\hline $\mathrm{Fe}$ & 34 & 19 & 0.132 & 0.014 & $1,107,390,244$ & $441,587,584$ & $77,882,9272$ & $27,409,997$ & & & 33031951.22 & 22740473.08 & & \\
\hline $\mathrm{Ga}$ & 553,902 & 133,817 & & & 51 & 34 & 15 & 9 & & & 1.61 & 1.19 & & \\
\hline $\mathrm{Ge}$ & 892,512 & 440,548 & & & 83 & 24 & 31 & 10 & & & 39.76 & 18.53 & & \\
\hline $\mathrm{Hg}$ & 8864 & 5451 & 0.117 & 0.060 & 4676 & 3026 & 1345 & 623 & 359 & 102 & 656.04 & 287.50 & & \\
\hline I & 12,078 & 5920 & & & 16,267 & 6001 & 4010 & 994 & & & & & & \\
\hline In & 301,685 & 230,323 & & & 214 & 201 & 46 & 39 & & & 0.97 & 0.38 & & \\
\hline $\mathrm{K}$ & 173 & 139 & 0.387 & 0.211 & $26,500,000$ & $4,225,044$ & $5,444,146$ & 768,007 & & & 334000.00 & 89569.53 & & \\
\hline $\mathrm{Li}$ & 3024 & 1221 & 0.279 & 0.093 & 171,854 & 100,673 & 2507 & 634 & & & & & & \\
\hline $\mathrm{Mg}$ & 3057 & 1231 & & & 375,463 & 152,610 & 129,473 & 24,204 & 21,155 & 9112 & 30125.00 & 9990.06 & & \\
\hline Mo & 16,435 & 18,649 & 0.250 & 0.038 & 123,500 & 42,641 & 23,658 & 8605 & & & 16229.02 & 8338.41 & & \\
\hline $\mathrm{Na}$ & 78 & 27 & & & $31,597,561$ & $7,239,043$ & $6,252,683$ & 374,940 & & & 211063.41 & 99330.59 & & \\
\hline $\mathrm{Ni}$ & 8672 & 6923 & 0.127 & 0.013 & $1,014,220$ & 310,851 & 200,049 & 31,207 & 62,315 & 23,864 & 50251.22 & 29974.81 & & \\
\hline $\mathrm{P}$ & 27 & 21 & 0.173 & 0.018 & $137,563,415$ & $19,908,287$ & $36,378,049$ & $5,698,224$ & & & & & & \\
\hline $\mathrm{Pb}$ & 951 & 581 & 0.134 & 0.041 & $3,347,073$ & 295,764 & $1,354,951$ & 213,767 & 817,024 & 255,341 & 122135.00 & 54522.23 & & \\
\hline $\mathrm{Pd}$ & $5,997,158$ & $4,860,139$ & 0.412 & 0.075 & 5460 & 1993 & 5498 & 2184 & 281 & 517 & 302.77 & 645.91 & 229.93 & 174.96 \\
\hline $\mathrm{Pt}$ & $16,692,622$ & $11,981,298$ & 0.605 & 0.057 & 134 & 44 & 4692 & 1908 & 390 & 533 & & & 408.65 & 237.34 \\
\hline $\mathrm{Re}$ & $1,192,390$ & 680,943 & & & 26 & 14 & 15 & 15 & & & & & & \\
\hline $\mathrm{Rh}$ & $44,528,264$ & $47,854,379$ & 0.613 & 0.057 & 536 & 151 & 580 & 206 & 50 & 71 & & & & \\
\hline $\mathrm{S}$ & 56 & 45 & & & $56,092,683$ & $6,879,004$ & $12,068,780$ & $1,383,865$ & & & 2041219.51 & 1839035.73 & & \\
\hline $\mathrm{Sb}$ & 3012 & 1579 & & & 96,973 & 43,108 & 35,590 & 7107 & 13,106 & 7014 & 7186.34 & 3309.67 & & \\
\hline $\mathrm{Si}$ & 1114 & 416 & & & $3,416,829$ & $1,419,522$ & 517,976 & 104,807 & & & 58014.63 & 30616.85 & & \\
\hline $\mathrm{Sn}$ & 10,346 & 4177 & 0.175 & 0.040 & 232,390 & 34,291 & 54,693 & 9973 & 9962 & 2222 & 13490.24 & 5549.74 & & \\
\hline $\mathrm{Sr}$ & 558 & 334 & & & 253,678 & 160,715 & 21,150 & 8404 & & & & & & \\
\hline $\mathrm{Ta}$ & 98,068 & 93,722 & 11.392 & 0.336 & 595 & 365 & 555 & 180 & 56 & 35 & 1802.31 & 164.12 & & \\
\hline $\mathrm{Ti}$ & 9701 & 4022 & 0.166 & 0.024 & & & 20,651 & 5991 & & & 5048.29 & 3468.53 & & \\
\hline V & 15,569 & 11,591 & 0.316 & 0.031 & 33,312 & 14,921 & 4506 & 1127 & & & 1657.90 & 1524.42 & & \\
\hline $\mathrm{W}$ & 13,710 & 8582 & 0.506 & 0.159 & 45,717 & 9259 & 10,171 & 2514 & 2597 & 1495 & 3237.80 & 1397.89 & & \\
\hline $\mathrm{Zn}$ & 1181 & 662 & 0.098 & 0.015 & $7,511,220$ & $1,855,243$ & $1,080,268$ & 153,463 & 101,256 & 39,329 & 412368.29 & 267076.76 & & \\
\hline $\mathrm{Zr}$ & 336 & 216 & 0.317 & 0.060 & 790,537 & 267,888 & 142,179 & 21,388 & & & 33360.61 & 7624.43 & & \\
\hline
\end{tabular}


Table 6. Descriptive statistics-economic factors (economic factors are applied to all materials).

\begin{tabular}{cccccccc}
\hline Lightaqua & \multicolumn{2}{c}{ LN_GDP } & \multicolumn{2}{c}{ US_Infla } & \multicolumn{3}{c}{ Interest } \\
\hline Mean & Std & Mean & Std & Mean & Std \\
& 10.28 & 0.35 & 4.48 & 2.96 & 4.61 & 3.76 &
\end{tabular}

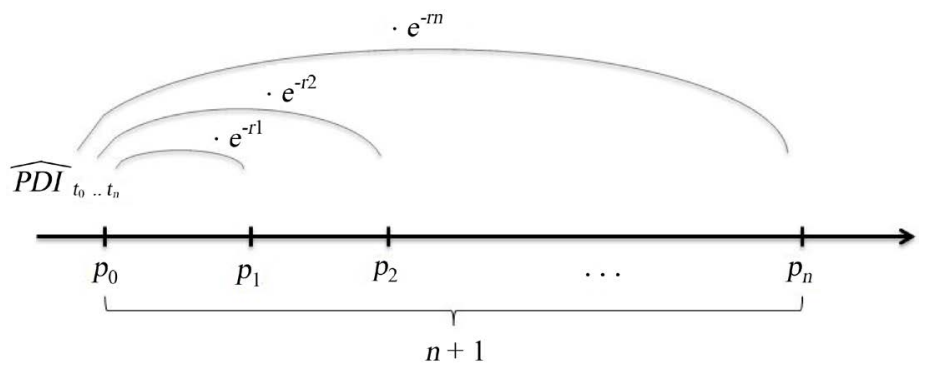

Figure 3. Graphical representation-creating price development index $\widehat{\mathrm{PDI}}_{t_{0 . t_{n}}}$.

$$
\widehat{\mathrm{PDI}}_{t_{0} . t_{n}} \widehat{\mathrm{PDI}}_{t_{0} . . t_{n}}=\frac{1}{n+1} \cdot \sum_{t=0}^{n} \widehat{\mathrm{PDI}}_{t}=\frac{1}{n+1} \cdot \sum_{t=0}^{n} \frac{p_{t} \cdot \mathrm{e}^{-r t}}{p_{0}}
$$

All parameters are the same, as introduced in formulas (1) and (2). With this method building an aggregated average price development indicator $\widehat{\mathrm{PDI}}_{t_{0} . t_{n}}$ it is possible to provide information about future price development, while avoiding the rather imprecise point measures. To illustrate it with an example, considering the silver price development (nominal) from $2010(t=0)$, where $p_{0}$ was $20.19\left(p_{0}\right)$, we observed average prices in $2011(t=1)$ of $35.12\left(p_{1}\right)$ and in $2012(t=2)$ of $30.27\left(p_{2}\right)$. World inflation in 2011 was nearly $5 \%$, which is the proxy we use for $r$. Hence, we can calculate $\widehat{\operatorname{PDI}}_{t_{0} . . t_{2}}$, see formula (3), and obtain a value of 1.5 for average price development, which indicates an increase of real prices within this period of more than $50 \%$.

Since not only price trend is critical for companies depending on raw materials, we integrate a second important measure determining supply risk from the economic perspective: the volatility of raw material prices. To make the absolute volatility comparable among all commodities, we use the coefficient of variation $(\mathrm{CV})$, the ratio of the standard deviation $\sigma$ to the mean $\bar{x}$ :

$$
\widehat{c v}_{t}=\frac{\sigma}{\bar{x}}
$$

In the following individual supply risk assessment models are structurally developed to enable predictions of future price and volatility development.

As most probably being one of the first quantitative studies analyzing the supply risk dimension of raw materials criticality with future price trend and volatility, including such a broad selection of metals over a long period of time, we use a classical linear regression. This well-known and popular method often provides a first useful approximation on potential correlations and weightings. To gain some basic insight on the importance of the single indicators for potential time-delayed impact on future price development and future volatility, we first conduct a linear regression for both measures on each indicator individually.

$$
\begin{aligned}
& \widehat{\mathrm{PDI}}_{t_{0} . t_{n}}=\beta_{0}+\beta_{i} \cdot \text { indicator }_{i}+\epsilon, \quad n=5 \\
& {\widehat{c v_{t_{0} . . t_{n}}}}=\beta_{0}+\beta_{i} \cdot \text {. indicator }_{i}+\epsilon, \quad n=5
\end{aligned}
$$

In all our computations, potential indicators are the independent variables indicator ${ }_{i}$, presented in Table 5 and Table 6. We regress those in separate models on the dependent variables $\widehat{\mathrm{PDI}}_{t_{0} . t_{n}}$ and $\widehat{c v}_{t_{0} . t_{n}}$. The forecast horizon $t_{0} . t_{n}$ thereby is expanded up to five successive years $n=5$, since an impact of current commodity key figures further into future seems rather implausible. The $\beta_{i}$ coefficients represent the marginal effect of indicator $_{i}$ on price development as well as future volatility. All models based on our data, are applied by the ordinary least squares (OLS) method. 
For each model, we tested the assumptions of the linear regression model, i.e. normality (Jarque-Bera test, [28]), heteroscedasticity (Breusch-Pagan test, [29]), autocorrelation (Durbin-Watson test, [30]) and, especially for the multiple regressions, multi-collinearity (Variance Inflation Factor, [31]). Due to the construction of both supply risk estimators, $\widehat{\mathrm{PDI}}$ and $\widehat{c v}$, autocorrelation in these two variables necessarily is present in some cases, and multi-collinearity appears for few commodities and factors, too.

In analogy to [10], we next implement multiple indicator models to improve relevance and precision (the major amount of the variation in future commodity price variation cannot be explained by only one indicator). Considering the requirements of the multiple regression equation, the number of independent variables has to be kept in proportion to the number of observations to avoid over-fitting and over-learning. For this reason, based on the results of the individual indicator examination of (6) and (7), theoretically suitable indicator ${ }_{i}$ with adequate performance in the basic model are included in the multivariate models. Of course, this selection is also limited by the data availability of some indicators. Hence, the following model formulas of (7) and (8) represent the maximum available selection of indicators. Applying the model calibration and indicator selection this way additionally ensures individualized models, taking into account resource specific characteristics. These models then determine how well the empirical selected sets of indicators in combination explain the commodity price trend and future volatility of a metal and to what extent each individual factor accounts for these changes. To identify supply risk patterns and determine the relative weights of each indicator, we use the following multivariate regression equations for each raw material:

$$
\begin{aligned}
& \widehat{\mathrm{PDI}}_{t_{0} . t_{n}}=\beta_{0}+\beta_{1} \cdot \text { HHI_Country }+\beta_{2} \cdot \operatorname{MineProd}+\beta_{3} \cdot \operatorname{AppConsum}+\beta_{4} \cdot X 2 \text { Prod }+\beta_{5} \cdot \text { Stocks } \\
& +\beta_{6} \cdot \mathrm{GDP}+\beta_{7} \cdot \mathrm{US} \_ \text {Infla }+\beta_{7} \cdot \text { Interest }+\beta_{8} \cdot \text { Future } 6+\epsilon, \quad n=5 \\
& {\widehat{c v_{t} . t_{n}}}=\beta_{0}+\beta_{1} \cdot \text { HHI_Country }+\beta_{2} \cdot \operatorname{MineProd}+\beta_{3} \cdot \text { AppConsum }+\beta_{4} \cdot X 2 \text { Prod }+\beta_{5} \cdot \text { Stocks } \\
& +\beta_{6} \cdot \mathrm{GDP}+\beta_{7} \cdot \mathrm{US} \_ \text {Infla }+\beta_{7} \cdot \text { Interest }+\beta_{8} \cdot \text { Future } 6+\epsilon, \quad n=5_{t_{0} . t_{n}}
\end{aligned}
$$

All model parametrization and data series remain unchanged. Regression assumptions were tested again. By the improved explanatory level the analysis allows the determination of commodity specify weights and importance. Therefore, the coefficients are standardized [10].

The $\beta_{i}$-non-standardized regression coefficients - are scale-dependent. Standardization is reached by multiplying the $\beta_{i}$ with the standard deviation of the exogenous variable, followed by a division through the standard deviation of the dependent variable:

$$
\beta_{i}^{\mathrm{norm}}=\beta_{i} * \frac{\sigma_{i}}{\sigma_{y}}
$$

where $\sigma_{i}$ is the standard deviation of indicator $i$, and $\sigma_{y}$ marks the standard deviation of the endogenous variable $\widehat{\mathrm{PDI}}_{t_{0} \cdots t_{n}}$ or $\hat{\sigma}_{t_{0} \cdots t_{n}}$. However, these standardized beta coefficients are not normalized, and thus do not directly show which proportion of the price makes up what indicator. Therefore, each indicator has to be normalized, by calculating the relative share of variation caused by the respective value of the explanatory power of the model $\left(R^{2}\right)$. In doing so, we obtain resource specific model weighting; that means which part of explanatory power can be assigned to what indicator.

$$
\text { weight }_{\beta_{i}^{\text {norm }}}=\frac{\left|\beta_{i}^{\text {norm }}\right|}{\sum_{j=i_{1}}^{i_{n}}\left|\beta_{j}^{\text {norm }}\right|} * R^{2}
$$

Now we are able to identify the main determinants for the commodity prices development and volatility.

\subsection{Out-of-Sample Test}

Correlations identified by the presented approach may be the result of overlearning, structural breaks or some sample random effects and thus would not be useful. To examine the existence of these effects, we conduct an out-of-sample test to analyze robustness, reliability and practical suitability of each model.

To ensure the robustness of our model, we implemented an out-of-sample test that performs the multiple regressions of (8) and (9) with a reduced dataset $(r d s)$, from which the last five years have been removed. We the- 
reby use the resulting $\beta_{i_{r d s}}$ values to compute estimated price trends and volatility for all elements of the complete dataset $(c d s)$, including the last five years, for which the reduced model has not been calibrated. The resulting values $\hat{x}_{t}^{\text {rds }}$ are compared once with the predicted values computed by the original models (see section 6), and once with the actual values of price trend and volatility from the excluded five years $n=5$, not included in rds. These benchmark values for each case are represented by $x_{t}^{\text {bench }}$. Furthermore, we compare the estimates $\hat{x}_{t}^{c d s}$, calculated from the complete dataset with the actual values $x_{t}^{\text {bench }}$. Evaluating the results, we distinguish between average relative deviation $\mathrm{ARD}_{c}$ and average absolute deviation $\mathrm{AAD}_{c}$ for a commodity $c$. In the first case, both positive as well as the negative deviation are aggregated. In the second case, deviation is computed from the absolute difference between benchmark and the respective estimator value. Correspondingly, the respective formulas are:

$$
\begin{aligned}
\mathrm{ARD}_{c} & =\frac{1}{n} \sum_{t=1}^{n}\left(\frac{x_{t}^{d s}}{x_{t}^{\text {bench }}}-1\right) \\
\mathrm{AAD}_{c} & =\frac{1}{n} \sum_{t=1}^{n}\left|\left(\frac{\hat{x}_{t}^{d s}}{x_{t}^{\text {bench }}}-1\right)\right|
\end{aligned}
$$

For all 42 materials $c$ the absolute as well as relative deviation values are accumulated to build the total average for each supply risk estimator $i$. The index $d s$ denotes the dataset from which the estimators are calculated, which is either the reduced $r d s$ or the complete dataset $c d s$.

$$
\begin{aligned}
& \mathrm{ARD}_{i}=\frac{1}{42} \sum_{c_{i}=c_{1}}^{42} \mathrm{ARD}_{c} \\
& \mathrm{AAD}_{i}=\frac{1}{42} \sum_{c_{i}=c_{1}}^{42} \mathrm{AAD}_{c}
\end{aligned}
$$

These results are important indicators for the validity of the models. However, differences between the results of the actual, the complete and the reduced dataset are unobjectionable, if there is a sound reason for these differences such as structural changes (e.g. new influence on prices, that could not be included within the reduced dataset.

\section{Results}

In this section, we present the results of our statistical supply risk assessment framework and our evolution procedures. At first, Section 3 describes the results of the two-stage OLS regression analysis, while the findings of the evaluation proceedings, which was introduced in Section 3, are explained in Section 4.

\subsection{Empirical Results}

The identification of an empirical connection between our supply risk estimator and potential indicators and hence the assessment of supply risks of raw materials, was performed by a two-stage regression analysis. Important characteristics for all material specific multivariate models can be found in Table 7 in aggregated form. This table shows the meaningfulness, the amount of significant indicators as well as the explanatory power of each supply risk estimator model of $\widehat{\mathrm{PDI}}_{t}$ and $\widehat{c v}_{t}$. All in all, the results of the multivariate models are heterogenous. While some materials, e.g. boron, copper, iron or silver show more than five significant variables and excellent levels of explanatory power up to $75 \%$, others, such as bromine, gallium, indium or rhenium only offer sporadic to no significance and little explanatory power, less than $3 \%$. For those materials, these results, thus indicate a potential selection bias. Moreover, rhenium is a special case as it performs above-average for the $\widehat{c v}{ }_{t}$ -models, however, price development $\widehat{\mathrm{PDI}}_{t}$ is not explainable at all. In general we observe a better explanatory power when extending the planning horizon. This is attributable to some effects. First of all, by extending the observation period the point estimation characteristics subsequently disappear. Secondly, we capture potential trend effects by the use of nominal prices. In addition, temporal impacts of indicators are detected with a rising probability. Furthermore, the coefficient of variation seems to be better explainable due to higher $R^{2}$-values. This could be caused by historical volatility effects: explosive increases cause a higher volatility and therefore larger deviation, which easier can be captured more easily by regression models. 
Table 7. Overview multiple regression-amount of significant variables and adjusted R2 (\#SV = number of significant variables).

\begin{tabular}{|c|c|c|c|c|c|c|c|c|c|c|c|c|c|c|c|c|c|c|c|c|}
\hline \multirow[b]{2}{*}{ Com } & \multicolumn{2}{|c|}{$\mathrm{PDI}_{1}$} & \multicolumn{2}{|c|}{$\mathbf{P D I}_{2}$} & \multicolumn{2}{|c|}{$\mathrm{PDI}_{3}$} & \multicolumn{2}{|c|}{$\mathrm{PDI}_{4}$} & \multicolumn{2}{|c|}{$\mathrm{PDI}_{5}$} & \multicolumn{2}{|c|}{$C V_{1}$} & \multicolumn{2}{|c|}{$\mathrm{CV}_{2}$} & \multicolumn{2}{|c|}{$\mathrm{CV}_{3}$} & \multicolumn{2}{|c|}{$\mathrm{CV}_{4}$} & \multicolumn{2}{|c|}{$C V_{5}$} \\
\hline & \#SV & $R^{2}$ & $\# \mathrm{SV}$ & $R^{2}$ & \#SV & $R^{2}$ & \#SV & $R^{2}$ & \#SV & $R^{2}$ & \#SV & $R^{2}$ & \#SV & $R^{2}$ & \#SV & $R^{2}$ & \#SV & $R^{2}$ & \#SV & $R^{2}$ \\
\hline $\mathrm{Ag}$ & & 0.12 & 1 & 0.14 & 2 & 0.25 & 3 & 0.36 & 4 & 0.50 & 4 & 0.31 & 4 & 0.18 & 5 & 0.21 & 6 & 0.44 & 6 & 0.66 \\
\hline $\mathrm{Al}$ & 1 & 0.06 & & & 1 & 0.09 & 1 & 0.13 & 1 & 0.16 & & & 3 & 0.06 & 5 & 0.28 & 6 & 0.51 & 6 & 0.66 \\
\hline As & 4 & 0.15 & 5 & 0.30 & 5 & 0.42 & 6 & 0.55 & 6 & 0.61 & & & 2 & 0.12 & 2 & 0.30 & 4 & 0.45 & 4 & 0.42 \\
\hline $\mathrm{Au}$ & 3 & 0.23 & 4 & 0.23 & 5 & 0.34 & 5 & 0.43 & 5 & 0.50 & 5 & 0.33 & 6 & 0.46 & 5 & 0.46 & 5 & 0.44 & 6 & 0.48 \\
\hline B & 4 & 0.41 & 4 & 0.50 & 4 & 0.60 & 5 & 0.68 & 5 & 0.71 & 1 & 0.14 & 4 & 0.31 & 5 & 0.45 & 5 & 0.63 & 5 & 0.73 \\
\hline $\mathrm{Be}$ & & & & & 2 & 0.23 & 3 & 0.32 & 4 & 0.41 & 0 & & 1 & 0.07 & 1 & 0.10 & 2 & 0.26 & 2 & 0.06 \\
\hline $\mathrm{Bi}$ & & & 1 & 0.05 & 2 & 0.11 & 3 & 0.20 & 3 & 0.16 & 0 & & & & 1 & 0.07 & 2 & 0.24 & 2 & 0.25 \\
\hline $\mathrm{Br}$ & & & & & & & 1 & 0.07 & 2 & 0.08 & 3 & 0.08 & 3 & 0.07 & 2 & 0.07 & 2 & 0.19 & 3 & 0.19 \\
\hline $\mathrm{Cd}$ & 1 & 0.05 & 1 & 0.10 & 1 & 0.14 & 2 & 0.17 & 3 & 0.17 & 3 & 0.04 & 5 & 0.19 & 5 & 0.28 & 5 & 0.45 & 5 & 0.58 \\
\hline $\mathrm{Co}$ & 1 & 0.09 & 1 & 0.15 & 1 & 0.23 & 2 & 0.32 & 3 & 0.36 & 0 & & & & 1 & 0.07 & 2 & 0.34 & 3 & 0.48 \\
\hline $\mathrm{Cr}$ & & & 1 & 0.07 & 1 & 0.10 & 1 & 0.14 & 2 & 0.20 & 1 & 0.06 & & & 2 & 0.21 & 2 & 0.27 & 2 & 0.26 \\
\hline $\mathrm{Cu}$ & 2 & 0.10 & 3 & 0.14 & 4 & 0.23 & 7 & 0.40 & 7 & 0.66 & 3 & 0.02 & 5 & 0.06 & 4 & 0.20 & 6 & 0.46 & 6 & 0.69 \\
\hline $\mathrm{Fe}$ & 4 & 0.43 & 4 & 0.52 & 4 & 0.57 & 4 & 0.57 & 3 & 0.59 & 3 & 0.26 & 2 & 0.31 & 3 & 0.39 & 3 & 0.35 & 3 & 0.27 \\
\hline $\mathrm{Ga}$ & & & & & 1 & 0.07 & 2 & 0.09 & 1 & 0.12 & 1 & 0.09 & 1 & 0.05 & & & & & & \\
\hline $\mathrm{Ge}$ & 1 & 0.05 & 1 & 0.11 & 1 & 0.10 & 2 & 0.17 & 3 & 0.20 & 1 & 0.29 & 1 & 0.26 & 1 & 0.20 & 3 & 0.42 & 4 & 0.44 \\
\hline $\mathrm{Hg}$ & 1 & 0.05 & 2 & 0.14 & 3 & 0.31 & 4 & 0.36 & 4 & 0.46 & 2 & 0.10 & 1 & 0.07 & 1 & 0.09 & 2 & 0.25 & 2 & 0.30 \\
\hline I & 1 & 0.05 & & & 1 & 0.07 & 1 & 0.11 & 1 & 0.16 & 1 & 0.05 & & & & & 1 & 0.08 & 1 & 0.18 \\
\hline In & 1 & 0.05 & 1 & 0.06 & 1 & 0.06 & 4 & 0.11 & 4 & 0.13 & & & 1 & 0.06 & 1 & 0.20 & 1 & 0.31 & 1 & 0.33 \\
\hline $\mathrm{K}$ & 3 & 0.16 & 1 & 0.08 & 1 & 0.14 & 1 & 0.26 & 1 & 0.31 & 2 & 0.14 & 1 & 0.08 & 2 & 0.19 & 1 & 0.18 & 1 & 0.19 \\
\hline $\mathrm{Li}$ & & & & & 2 & 0.13 & 2 & 0.17 & 1 & 0.13 & 1 & 0.07 & 2 & 0.04 & 2 & 0.07 & 3 & 0.11 & 3 & 0.24 \\
\hline $\mathrm{Mg}$ & 1 & 0.07 & 1 & 0.16 & 3 & 0.25 & 3 & 0.37 & 4 & 0.57 & 2 & 0.17 & 2 & 0.21 & 4 & 0.47 & 4 & 0.76 & 3 & 0.40 \\
\hline $\mathrm{Mn}$ & 1 & 0.05 & 2 & 0.12 & 3 & 0.31 & 4 & 0.35 & 5 & 0.50 & 2 & 0.37 & 3 & 0.43 & 2 & 0.31 & 3 & 0.22 & 1 & 0.13 \\
\hline Mo & 2 & 0.21 & 2 & 0.23 & 2 & 0.23 & 1 & 0.12 & 2 & 0.16 & 2 & 0.13 & 2 & 0.11 & 2 & 0.08 & 3 & 0.19 & 3 & 0.27 \\
\hline $\mathrm{Na}$ & 3 & 0.30 & 3 & 0.36 & 3 & 0.47 & 3 & 0.52 & 5 & 0.57 & 3 & 0.12 & 4 & 0.14 & 5 & 0.30 & 5 & 0.46 & 5 & 0.53 \\
\hline $\mathrm{Ni}$ & & & & & 1 & 0.07 & 2 & 0.11 & 4 & 0.12 & 5 & 0.24 & 6 & 0.31 & 6 & 0.28 & 5 & 0.23 & 4 & 0.26 \\
\hline $\mathrm{P}$ & 2 & 0.14 & 1 & 0.07 & 2 & 0.20 & 3 & 0.30 & 3 & 0.23 & 1 & 0.12 & 1 & 0.15 & 2 & 0.21 & 3 & 0.30 & 3 & 0.30 \\
\hline $\mathrm{Pb}$ & 2 & 0.15 & 2 & 0.25 & 2 & 0.33 & 2 & 0.38 & 2 & 0.37 & 2 & 0.12 & 2 & 0.26 & 3 & 0.27 & 5 & 0.45 & 6 & 0.54 \\
\hline $\mathrm{Pd}$ & & & & & 1 & 0.05 & 2 & 0.33 & 3 & 0.39 & 1 & 0.09 & 1 & 0.18 & 4 & 0.45 & 4 & 0.28 & 5 & 0.41 \\
\hline $\mathrm{Pt}$ & 1 & 0.08 & 1 & 0.08 & 2 & 0.13 & 3 & 0.20 & 3 & 0.27 & 4 & 0.24 & 3 & 0.08 & 5 & 0.39 & 5 & 0.51 & 4 & 0.40 \\
\hline $\mathrm{Re}$ & & & & & & & & & & & 3 & 0.50 & 3 & 0.44 & 4 & 0.41 & 5 & 0.49 & 5 & 0.66 \\
\hline $\mathrm{Rh}$ & & & 1 & 0.06 & 2 & 0.13 & 3 & 0.19 & 5 & 0.38 & 1 & 0.10 & 5 & 0.20 & 4 & 0.20 & 3 & 0.25 & 4 & 0.39 \\
\hline $\mathrm{S}$ & 4 & 0.21 & 1 & 0.06 & 1 & 0.15 & 3 & 0.37 & 2 & 0.24 & 3 & 0.20 & 3 & 0.23 & 3 & 0.23 & 3 & 0.28 & 5 & 0.47 \\
\hline $\mathrm{Sb}$ & & & & & 1 & 0.05 & 1 & 0.05 & 1 & 0.06 & & & 1 & 0.06 & & & & & 2 & 0.15 \\
\hline $\mathrm{Si}$ & & & & & 2 & 0.21 & 3 & 0.22 & 4 & 0.24 & 3 & 0.16 & 2 & 0.22 & 3 & 0.27 & 3 & 0.27 & 3 & 0.32 \\
\hline $\mathrm{Sn}$ & 2 & 0.16 & 4 & 0.23 & 5 & 0.35 & 5 & 0.46 & 5 & 0.54 & 2 & 0.18 & 2 & 0.21 & 3 & 0.31 & 5 & 0.40 & 5 & 0.41 \\
\hline $\mathrm{Sr}$ & & & 1 & 0.14 & 2 & 0.20 & 2 & 0.18 & 3 & 0.46 & 2 & 0.15 & 2 & 0.20 & 2 & 0.17 & 2 & 0.17 & 2 & 0.15 \\
\hline $\mathrm{Ta}$ & & & & & 1 & 0.05 & 2 & 0.14 & 3 & 0.27 & 1 & 0.30 & 2 & 0.21 & 2 & 0.19 & 2 & 0.15 & 2 & 0.13 \\
\hline $\mathrm{Ti}$ & 2 & 0.21 & 1 & 0.19 & 2 & 0.28 & 2 & 0.36 & 2 & 0.42 & & & & & 1 & 0.16 & 2 & 0.24 & 5 & 0.27 \\
\hline V & 1 & 0.26 & 1 & 0.34 & 1 & 0.19 & 2 & 0.18 & 3 & 0.17 & 4 & 0.21 & 4 & 0.47 & 4 & 0.44 & 4 & 0.50 & 4 & 0.60 \\
\hline W & 2 & 0.17 & 3 & 0.21 & 3 & 0.29 & 3 & 0.33 & 5 & 0.37 & & & & & 1 & 0.07 & 3 & 0.06 & 4 & 0.14 \\
\hline $\mathrm{Zn}$ & & & 1 & 0.06 & 1 & 0.08 & 2 & 0.16 & 3 & 0.34 & 4 & 0.04 & 6 & 0.19 & 5 & 0.45 & 4 & 0.52 & 4 & 0.55 \\
\hline $\mathrm{Zr}$ & 1 & 0.05 & 1 & 0.06 & 1 & 0.05 & 4 & 0.09 & 4 & 0.07 & & & & & 2 & 0.12 & 3 & 0.14 & 2 & 0.05 \\
\hline Average & & 0.15 & & 0.17 & & 0.21 & & 0.27 & & 0.33 & & 0.17 & & 0.19 & & 0.25 & & 0.33 & & 0.36 \\
\hline
\end{tabular}


Next, we take a closer look at the multi-indicator regression models, where we exemplary show the results for the longest examined observation period $(t=5)$. Hence, Table 8 displays beta values, standardized weights and explanatory power for price trend estimator $\widehat{\mathrm{PDI}}_{5}$-models, respective does Table 9 for the models of the coefficient of estimation $c v_{5}$. All presented indicator values in this tables, as previously described, show significant influence in the single regression analysis. Regarding the quality of potential indicators to estimate future price development, shown in detail in Table 8, in absolute figures interest rate shows the best performance within a planning horizon of five years. The respective indicator shows significant influence for 29 out of 42 raw materials (69\%), with a $9.5 \%$ average share of explanatory power. Hence, the interest rate shows the third best estimator function for the observation period of five years. This may refer to the general function of interest rates as a long term economic regulator. Thus, Hotelling's rule could have some justification after all. Furthermore, considering the relative weighting, secondary production and country concentration seem to be the most important drivers for $\widehat{\mathrm{PDI}}_{5}$, as they show the highest average weights of $11.1 \%$ and $9.9 \%$. The recycling volume, which has largely increased over the past ten to twenty years, appears to be more than acceptable as a midterm price development indicator. The temporal lagged impact of recycling may be caused by several time consuming and complex processing steps, such as collecting the old product, screening and dissembling the respective parts, refining the materials, and finally converting it into a high grade secondary raw material. For this reason the recycling volume can, to a certain extent, react to midterm price development. Besides, the significant and high values of country concentration emphasize the strong influence of economic monopolies and political structures on global commodity markets, even for longer observation periods. Thus, the lagged impact illustrates that geographical fragmentation of minerals production is rather rigid and inflexible. The specific commodity market indicator future 6 shows a relative weighting of $7.3 \%$ and thus surprisingly indicates future price development even originally inlaid for far shorter time frames. The relative influence of mine production is $5.6 \%$. Although significant for a high number of materials (21 out of 41 materials) this value is on a fairly low level. Due to its, sometimes quite vast differences in yearly production volume, mine production is supposed to be a rather short-term indicator. Looking at the indicators representing demand, World GDP as well as apparent consumption show a still valuable performance, with 18 respective 19 significant values out of 42 possible and average weightings of $6.7 \%$ (GDP) and $4.6 \%$ (US consumption). With the lowest result the US proxy for inflation with a $4.1 \%$ share of explanation is only partially suitable. Considering future volatility trend (Table 9) in absolute numbers, again the interest rate offers the highest amount of significant variables with 25 of $42(60 \%)$, while showing the second best relative weighting of $8.1 \%$. Stocks have the highest share of explanatory power, with an average weighting of $10.3 \%$. In addition, in most examined cases the respective absolute value of $\beta$ is negative, which implies that with increasing stock volumes, volatility reduces in the markets, and vice versa. Being significant in 23 of 42 cases World GDP with an average share of explanatory power of $7.3 \%$ on $c v_{5}$ again is the better part of the analyzed demand indicators. Thus, world economy strongly influences the diverse commodity markets, as many investors and producers may rely on this main indicator for planning future mine investments or production levels. Despite this, apparent consumption as a US demand proxy should not be underestimated, with a relative share of explanation of $6.5 \%$. Nowadays, usually China with its expanding demand is assigned to be a stronger demand driver. The still important impact of the U.S. in terms of consumption as volatility estimator could however be a historical relict, since our study extends to 41 years. Back then, China did not have as strong an impact on the markets as it does today. Country concentration also affects future fluctuations with an average weight of $7.5 \%$ in 13 out of 26 significant test results. Even with an average weight of $6.6 \%$ mine production explains more of future fluctuation than of price development, while showing a similar pattern as in price development, not offering the best mid-term indication qualities. Considering secondary production and inflation, both USA proxies show a 5.5\% share of explanatory power. Whereas recycling offers much less prediction quality as explained before, and thus, serves much well as price trend indicator. Hence, suitability of US inflation for both supply risk estimators from a general perspective is moderate. Lastly, future6 is the estimator, which shows the poorest estimator quality with a relative share of $3.9 \%$. This is a reasonable result as six month futures are capable of indicating short-term rather than long-term fluctuations.

All indicators for both supply risk proxies generally show a large number of significant variables and relative weightings with a still considerable minimum average around $4 \%$ in the cases of inflation ( $\left.\widehat{\mathrm{PDI}}_{5}\right)$ and future 6 $\left(\widehat{c v_{5}}\right)$. Thus, for none of the examined quantitative indicators suitability as a supply risk estimators can be denied. Nevertheless, due to significant differences between the observed raw materials, an indicator specific analysis of the presented results is required. 
Table 8. Multiple regression results-beta values, standardized weights and explanatory power of $\widehat{\mathrm{PDI}}_{5}-\mathrm{models}(\mathrm{AVG}=\mathrm{average}$, $\# \mathrm{SV}=$ number of significant variables).

\begin{tabular}{|c|c|c|c|c|c|c|c|c|c|c|c|c|c|c|c|c|c|c|c|}
\hline \multirow[b]{2}{*}{ Com } & \multicolumn{2}{|c|}{ HHI_Country } & \multicolumn{2}{|c|}{ MineProd } & \multicolumn{2}{|c|}{ AppConsum } & \multicolumn{2}{|l|}{ 2Prod } & \multicolumn{2}{|l|}{ Stocks } & \multicolumn{2}{|l|}{ In_GDP } & \multicolumn{2}{|c|}{ US_Infla } & \multicolumn{2}{|c|}{ Interest } & \multicolumn{2}{|c|}{ future6 } & \multirow[b]{2}{*}{$R^{2}$} \\
\hline & $\beta$ & $w$ & $\beta$ & $w$ & $\beta$ & $w$ & $\beta$ & $w$ & $\beta$ & $w$ & $\beta$ & $w$ & $\beta$ & $w$ & $\beta$ & $w$ & $\beta$ & $w$ & \\
\hline $\mathrm{Ag}$ & & & & & 0.00001339 & $1.7 \%$ & & & 0.00009823 & $13.3 \%$ & & & & & -0.058 & $26.5 \%$ & -0.0137 & $8.1 \%$ & $49.6 \%$ \\
\hline $\mathrm{Al}$ & & & & & & & & & & & & & & & -0.021 & $16.0 \%$ & & & $16.0 \%$ \\
\hline As & & & -0.00001109 & $17.2 \%$ & -0.00000563 & $4.6 \%$ & & & 0.00003033 & $11.2 \%$ & -0.25710975 & $12.1 \%$ & 0.004 & $1.8 \%$ & -0.023 & $13.8 \%$ & & & $60.8 \%$ \\
\hline $\mathrm{Au}$ & & & 0.00018827 & $8.0 \%$ & & & -0.01177457 & $14.0 \%$ & & & -0.581406501 & $14.5 \%$ & & & -0.041 & $13.1 \%$ & 0.0001 & $0.8 \%$ & $50.4 \%$ \\
\hline B & & & -0.00000001 & $4.7 \%$ & 0.00000054 & $16.8 \%$ & & & & & -0.203871052 & $21.6 \%$ & 0.014 & $14.0 \%$ & -0.010 & $14.0 \%$ & & & $71.1 \%$ \\
\hline $\mathrm{Be}$ & & & -0.00023471 & $3.4 \%$ & -0.00118416 & $16.3 \%$ & & & & & -0.23435038 & $11.1 \%$ & 0.021 & $9.7 \%$ & & & & & $40.6 \%$ \\
\hline $\mathrm{Bi}$ & & & 0.00023011 & $8.6 \%$ & & & & & & & 0.04166994 & $0.7 \%$ & -0.038 & $6.4 \%$ & & & & & $15.8 \%$ \\
\hline $\mathrm{Br}$ & & & 0.00000006 & $0.6 \%$ & 0.00000165 & $6.9 \%$ & & & & & & & & & & & & & $7.5 \%$ \\
\hline $\mathrm{Cd}$ & & & & & 0.00004327 & $1.8 \%$ & & & & & 0.75881468 & $7.0 \%$ & -0.099 & $8.7 \%$ & & & & & $17.4 \%$ \\
\hline Co & & & & & & & -0.00029695 & $14.0 \%$ & & & 0.45727195 & $6.8 \%$ & & & -0.080 & $15.1 \%$ & & & $35.8 \%$ \\
\hline $\mathrm{Cu}$ & -8.550 & $14.9 \%$ & 0.00000005 & $10.8 \%$ & & & -0.00000241 & $20.6 \%$ & 0.00000059 & $10.8 \%$ & 0.04698605 & $1.1 \%$ & 0.020 & $4.5 \%$ & -0.010 & $2.9 \%$ & & & $65.5 \%$ \\
\hline $\mathrm{Fe}$ & & & 0.00000000 & $24.0 \%$ & 0.00000001 & $23.4 \%$ & & & & & & & & & -0.016 & $11.3 \%$ & & & $58.8 \%$ \\
\hline $\mathrm{Ga}$ & & & & & & & & & & & & & -0.019 & $11.5 \%$ & & & & & $11.5 \%$ \\
\hline $\mathrm{Ge}$ & & & & & -0.00431584 & $2.1 \%$ & & & & & & & 0.045 & $9.3 \%$ & -0.030 & $8.2 \%$ & & & $19.5 \%$ \\
\hline $\mathrm{Hg}$ & & & -0.00001344 & $2.4 \%$ & & & & & 0.00085988 & $15.9 \%$ & 0.83234956 & $15.6 \%$ & & & -0.050 & $11.9 \%$ & & & $45.8 \%$ \\
\hline I & & & & & & & & & & & & & & & -0.033 & $16.3 \%$ & & & $16.3 \%$ \\
\hline In & & & -0.00286274 & $3.8 \%$ & 0.02020410 & $5.3 \%$ & & & -0.64922356 & $2.5 \%$ & & & -0.050 & $1.4 \%$ & & & & & $13.0 \%$ \\
\hline $\mathrm{K}$ & & & & & & & & & & & & & & & -0.036 & $30.9 \%$ & & & $30.9 \%$ \\
\hline $\mathrm{Li}$ & & & & & & & & & & & & & & & -0.027 & $13.1 \%$ & & & $13.1 \%$ \\
\hline $\mathrm{Mg}$ & & & & & -0.00000028 & $0.8 \%$ & -0.00003083 & $36.5 \%$ & & & 0.50751978 & $19.3 \%$ & & & 0.000 & $0.1 \%$ & & & $56.7 \%$ \\
\hline $\mathrm{Mn}$ & & & 0.00000010 & $4.9 \%$ & -0.00000015 & $1.8 \%$ & & & 0.00000037 & $24.6 \%$ & \% 1.31721264 & $19.1 \%$ & & & 0.000 & $0.1 \%$ & & & $50.5 \%$ \\
\hline $\mathrm{Ni}$ & & & -0.00000018 & $1.7 \%$ & & & 0.00000435 & $3.7 \%$ & -0.00000178 & $2.1 \%$ & & & -0.041 & $4.8 \%$ & & & & & $12.3 \%$ \\
\hline $\mathrm{P}$ & & & 0.00000000 & $1.1 \%$ & -0.00000002 & $11.8 \%$ & & & & & & & & & -0.028 & $9.9 \%$ & & & $22.9 \%$ \\
\hline $\mathrm{Pb}$ & & & & & & & & & & & & & -0.029 & $14.9 \%$ & -0.033 & $22.0 \%$ & & & $36.9 \%$ \\
\hline $\mathrm{Pd}$ & & & 0.00017279 & $17.6 \%$ & & & & & -0.00010206 & $3.2 \%$ & & & & & & & -0.00221 & $18.1 \%$ & 6 $39.0 \%$ \\
\hline $\mathrm{Pt}$ & -1.000 & $6.4 \%$ & & & & & & & & & & & & & -0.023 & $9.8 \%$ & -0.00081 & $10.3 \%$ & $626.5 \%$ \\
\hline $\operatorname{Re}$ & & & & & & & & & & & & & & & & & & & \\
\hline $\mathrm{Rh}$ & & & 0.00887062 & $9.1 \%$ & -0.00810638 & $10.7 \%$ & 0.02994515 & $9.9 \%$ & & & -2.69059982 & $6.5 \%$ & -0.063 & $1.5 \%$ & & & & & $37.7 \%$ \\
\hline S & & & & & -0.00000009 & $9.6 \%$ & & & & & & & & & -0.048 & $14.0 \%$ & & & $23.7 \%$ \\
\hline $\mathrm{Sb}$ & & & & & & & & & & & & & -0.041 & $6.2 \%$ & & & & & $6.2 \%$ \\
\hline $\mathrm{Si}$ & & & 0.00000000 & $0.1 \%$ & -0.00000039 & $5.3 \%$ & & & & & -0.14283230 & $8.0 \%$ & & & -0.015 & $10.6 \%$ & & & $24.0 \%$ \\
\hline $\mathrm{Sn}$ & 2.459 & $14.1 \%$ & 0.00000074 & $3.3 \%$ & -0.00000107 & $1.5 \%$ & & & 0.00002433 & $19.4 \%$ & & & & & -0.028 & $16.0 \%$ & & & $54.3 \%$ \\
\hline $\mathrm{Sr}$ & & & 0.00000338 & $17.4 \%$ & 0.00001312 & $3.9 \%$ & & & & & -2.077635212 & $24.7 \%$ & & & & & & & $46.1 \%$ \\
\hline $\mathrm{Ta}$ & & & & & & & & & 0.00097544 & $9.7 \%$ & -0.47309628 & $8.4 \%$ & & & -0.040 & $8.9 \%$ & & & $27.0 \%$ \\
\hline $\mathrm{Ti}$ & & & & & -0.00000804 & $8.4 \%$ & & & & & & & & & -0.043 & $34.0 \%$ & & & $42.4 \%$ \\
\hline $\mathrm{V}$ & 9.099 & $8.6 \%$ & & & & & & & -0.00006208 & $2.8 \%$ & 0.63379857 & $5.8 \%$ & & & & & & & $17.2 \%$ \\
\hline W & 0.492 & $4.4 \%$ & & & & & -0.00009415 & $6.9 \%$ & -0.00018668 & $12.9 \%$ & & & -0.024 & $3.8 \%$ & -0.042 & $8.9 \%$ & & & $36.9 \%$ \\
\hline $\mathrm{Zn}$ & 14.411 & $15.6 \%$ & 0.00000006 & $8.0 \%$ & & & & & & & & & & & -0.022 & $10.2 \%$ & & & $33.8 \%$ \\
\hline $\mathrm{Zr}$ & & & -0.00000022 & $1.5 \%$ & & & & & 0.00000812 & $2.1 \%$ & -0.08015923 & $0.8 \%$ & & & -0.021 & $2.6 \%$ & & & $7.1 \%$ \\
\hline $\begin{array}{c}\# \mathrm{SV}< \\
0.1\end{array}$ & & 8 & 21 & & 19 & & 7 & & 14 & & 18 & & 1 & & 2 & 9 & 4 & & \\
\hline AVG $w$ & 9.9 & $9 \%$ & $5.6 \%$ & & $4.6 \%$ & & $11.1 \%$ & & $8.4 \%$ & & $6.7 \%$ & & 4.1 & $1 \%$ & 9.5 & $5 \%$ & $7.1 \%$ & & $32.5 \%$ \\
\hline
\end{tabular}


Table 9. Multiple regression results-beta values, standardized weights and explanatory power of $\mathrm{b} \widehat{c v_{5}}-$ models $(\mathrm{AVG}=\mathrm{average}, \# \mathrm{SV}=$ number of significant variables).

\begin{tabular}{|c|c|c|c|c|c|c|c|c|c|c|c|c|c|c|c|c|c|c|c|}
\hline \multirow[b]{2}{*}{ Com } & \multicolumn{2}{|c|}{ HHI_Country } & \multicolumn{2}{|c|}{ MineProd } & \multicolumn{2}{|c|}{ AppConsum } & \multicolumn{2}{|l|}{ 2Prod } & \multicolumn{2}{|l|}{ Stocks } & \multicolumn{2}{|c|}{ In_GDP } & \multicolumn{2}{|c|}{ US_Infla } & \multicolumn{2}{|c|}{ Interest } & \multicolumn{2}{|l|}{ future6 } & \multirow[b]{2}{*}{$R^{2}$} \\
\hline & $\beta$ & $w$ & $\beta$ & $w$ & $\beta$ & $w$ & $\beta$ & $w$ & $\beta$ & $w$ & $\beta$ & $w$ & $\beta$ & $w$ & $\beta$ & $w$ & $\beta$ & $w$ & \\
\hline $\mathrm{Ag}$ & 11.39 & $6.0 \%$ & 0.00001707 & $11.1 \%$ & & & 0.00019116 & $13.6 \%$ & & & -0.2279 & $13.1 \%$ & 0.0162 & $9.0 \%$ & -0.01761 & $12.8 \%$ & & & $65.5 \%$ \\
\hline $\mathrm{Al}$ & -0.53 & $0.7 \%$ & -0.00000001 & $9.9 \%$ & 0.00000001 & $0.8 \%$ & -0.00000019 & $24.6 \%$ & & & 0.5943 & $27.5 \%$ & & & -0.0037 & $2.2 \%$ & & & $65.7 \%$ \\
\hline As & & & & & -0.00000205 & $3.9 \%$ & & & 0.00000859 & $7.2 \%$ & -0.0995 & $10.6 \%$ & & & -0.01492 & $20.1 \%$ & & & $41.9 \%$ \\
\hline $\mathrm{Au}$ & & & -0.00002400 & $3.2 \%$ & & & -0.00379530 & $14.1 \%$ & & & -0.0258 & $2.0 \%$ & 0.0119 & $8.8 \%$ & -0.02011 & $19.7 \%$ & -0.0000100 & $0.2 \%$ & $48.1 \%$ \\
\hline $\mathrm{B}_{-}$ & & & 0.00000002 & $11.1 \%$ & 0.00000016 & $6.5 \%$ & & & & & -0.2494 & $35.7 \%$ & 0.0028 & $3.8 \%$ & -0.00871 & $15.8 \%$ & & & $72.9 \%$ \\
\hline $\mathrm{Be}$ & & & & & & & & & -0.00068918 & $4.0 \%$ & 0.0893 & $2.5 \%$ & & & & & & & $6.5 \%$ \\
\hline $\mathrm{Bi}$ & & & 0.00012611 & $14.0 \%$ & & & & & & & & & 0.0217 & $10.7 \%$ & & & & & $24.7 \%$ \\
\hline $\mathrm{Br}$ & & & 0.00000036 & $5.2 \%$ & 0.00000120 & $6.8 \%$ & & & & & -0.1600 & $6.9 \%$ & & & & & & & $18.9 \%$ \\
\hline $\mathrm{Cd}$ & & & 0.00004202 & $10.5 \%$ & -0.00008988 & $19.0 \%$ & & & -0.00015994 & $14.2 \%$ & -0.1339 & $6.4 \%$ & -0.0171 & $7.8 \%$ & & & & & $57.8 \%$ \\
\hline Co & & & & & & & & & & & 0.1169 & $7.5 \%$ & 0.04162 & $25.5 \%$ & -0.01841 & $15.0 \%$ & & & $48.0 \%$ \\
\hline $\mathrm{Cu}$ & -1.75 & $6.4 \%$ & -0.00000003 & $10.8 \%$ & & & -0.00000078 & $14.0 \%$ & 0.00000031 & $12.1 \%$ & 0.4211 & $21.0 \%$ & 0.0102 & $4.8 \%$ & & & & & $69.1 \%$ \\
\hline $\mathrm{Fe}$ & 1.79 & $7.5 \%$ & 0.00000000 & $6.8 \%$ & & & & & & & & & & & -0.00941 & $12.2 \%$ & & & $26.5 \%$ \\
\hline \multicolumn{20}{|l|}{$\mathrm{Ga}$} \\
\hline $\mathrm{Ge}$ & & & & & -0.01222935 & $17.0 \%$ & & & 0.00142428 & $5.0 \%$ & 0.3056 & $18.8 \%$ & & & -0.0043 & $3.3 \%$ & & & $44.1 \%$ \\
\hline $\mathrm{Hg}$ & 1.07 & $15.3 \%$ & & & & & & & & & & & & & -0.01581 & $14.3 \%$ & & & $29.6 \%$ \\
\hline $\mathrm{I}_{-}$ & & & & & & & & & & & & & & & -0.01401 & $17.7 \%$ & & & $17.7 \%$ \\
\hline In & & & & & & & & & -0.29073847 & $33.0 \%$ & & & & & & & & & $33.0 \%$ \\
\hline $\mathrm{K}_{-}$ & & & & & & & & & & & & & & & -0.01501 & $19.4 \%$ & & & $19.4 \%$ \\
\hline $\mathrm{Li}$ & & & 0.00000176 & $15.0 \%$ & & & & & & & -0.1355 & $5.4 \%$ & -0.0094 & $3.6 \%$ & & & & & $24.0 \%$ \\
\hline $\mathrm{Mg}$ & & & & & & & -0.00000460 & $15.1 \%$ & -0.00000457 & $16.4 \%$ & & & & & -0.0062 & $8.2 \%$ & & & $39.7 \%$ \\
\hline $\mathrm{Mn}$ & & & & & & & & & & & & & & & -0.01511 & $12.7 \%$ & & & $12.7 \%$ \\
\hline $\mathrm{Ni}$ & & & -0.00000011 & $4.2 \%$ & & & 0.00000245 & $8.4 \%$ & & & 0.0321 & $1.6 \%$ & -0.0257 & $12.2 \%$ & & & & & $26.4 \%$ \\
\hline $\mathrm{P}_{-}$ & & & 0.00000000 & $0.3 \%$ & -0.00000001 & $16.7 \%$ & & & & & & & & & -0.01591 & $13.5 \%$ & & & $30.4 \%$ \\
\hline $\mathrm{Pb}$ & 2.36 & $15.7 \%$ & -0.00000012 & $6.6 \%$ & -0.00000032 & $16.2 \%$ & & & 0.00000035 & $4.3 \%$ & & & 0.0036 & $2.5 \%$ & -0.0091 & $8.3 \%$ & & & $53.6 \%$ \\
\hline $\mathrm{Pd}$ & 1.05 & $12.1 \%$ & 0.00000521 & $2.1 \%$ & 0.00003758 & $15.5 \%$ & & & & & & & & & -0.0115 & $9.3 \%-$ & -0.0000732 & $2.3 \%$ & $41.3 \%$ \\
\hline $\mathrm{Pt}$ & & & & & & & & & & & 0.1337 & $7.7 \%$ & 0.0277 & $15.2 \%$ & -0.0103 & $7.5 \%$ & -0.0004039 & $9.5 \%$ & $39.9 \%$ \\
\hline $\mathrm{Re}$ & & & -0.01268114 & $19.6 \%$ & 0.00151442 & $1.9 \%$ & & & & & 0.1534 & $6.0 \%$ & 0.05332 & $20.1 \%$ & -0.03671 & $18.3 \%$ & & & $65.9 \%$ \\
\hline $\mathrm{Rh}$ & -0.98 & $10.7 \%$ & & & & & -0.00013544 & $1.2 \%$ & & & 0.2717 & $17.9 \%$ & -0.0142 & $9.0 \%$ & & & & & $38.8 \%$ \\
\hline $\mathrm{S}_{-}$ & & & 0.00000006 & $19.9 \%$ & & & & & -0.00000003 & $3.2 \%$ & -0.6178 & $12.1 \%$ & -0.0250 & $4.7 \%$ & -0.0305 & $7.6 \%$ & & & $47.5 \%$ \\
\hline $\mathrm{Sb}$ & & & & & 0.00000584 & $6.7 \%$ & & & & & & & -0.0149 & $8.1 \%$ & & & & & $14.7 \%$ \\
\hline $\mathrm{Si}$ & & & & & & & & & -0.00000089 & $12.8 \%$ & & & -0.0033 & $5.0 \%$ & -0.00701 & $14.1 \%$ & & & $31.9 \%$ \\
\hline Sn & 0.93 & $12.0 \%$ & 0.00000097 & $9.7 \%$ & 0.00000091 & $2.8 \%$ & & & 0.00000648 & $11.6 \%$ & & & & & -0.0034 & $4.4 \%$ & & & $40.5 \%$ \\
\hline $\mathrm{Sr}$ & & & & & -0.00000382 & $8.5 \%$ & & & & & -0.0744 & $6.6 \%$ & & & & & & & $15.1 \%$ \\
\hline $\mathrm{Ta}$ & 0.28 & $6.4 \%$ & & & & & 0.00290934 & $6.8 \%$ & & & & & & & & & & & $13.2 \%$ \\
\hline $\mathrm{Ti}$ & -2.86 & $4.1 \%$ & -0.00001770 & $1.3 \%$ & & & & & & & 0.8310 & $14.6 \%$ & -0.0240 & $4.0 \%$ & 0.0155 & $3.4 \%$ & & & $27.4 \%$ \\
\hline $\mathrm{V}_{-}$ & & & 0.00000268 & $8.2 \%$ & & & & & -0.00008534 & $31.1 \%$ & 0.2541 & $18.8 \%$ & -0.0032 & $2.3 \%$ & & & & & $60.5 \%$ \\
\hline $\mathrm{W}_{-}$ & 0.22 & $6.6 \%$ & & & 0.00000584 & $2.3 \%$ & 0.00001641 & $3.9 \%$ & -0.00000534 & $1.2 \%$ & & & & & & & & & $14.1 \%$ \\
\hline $\mathrm{Zn}$ & -1.26 & $1.0 \%$ & 0.00000026 & $26.8 \%$ & & & & & & & -0.9103 & $23.4 \%$ & -0.0170 & $4.2 \%$ & & & & & $55.3 \%$ \\
\hline $\mathrm{Zr}$ & & & -0.00000007 & $1.3 \%$ & & & & & & & -0.1235 & $3.3 \%$ & & & & & & & $4.5 \%$ \\
\hline $\begin{array}{l}\# \mathrm{SV}< \\
\mathbf{0 . 1}\end{array}$ & 13 & & 22 & & 16 & & 9 & & 14 & & 23 & & 21 & & 25 & & 3 & & \\
\hline AVG $w$ & 7.5 & & $6.6 \%$ & & $6.5 \%$ & & $5.5 \%$ & & $10.3 \%$ & & $7.3 \%$ & & $5.5 \%$ & & $8.1 \%$ & & $3.9 \%$ & & $36.4 \%$ \\
\hline
\end{tabular}


Therefore, applying the results to create individual calibrated models, we calculate both supply risk estimators $\widehat{\mathrm{PDI}}_{t}$ and $\widehat{c v}_{t}$ for each raw material, based on the indicator's latest available figures of 2010. Following the previous proceeding, the results of the five year planning horizon are explained in detail. The resulting estimator values as well as corresponding coefficients of determination are presented in Table $\mathbf{1 0}$.

Furthermore, these results are graphically represented in Figure 4. We thereby follow existing criticality stu-

Table 10. Overview of price development indicator and coefficient of variation for planning period of five years calculated from data of $2010\left(\neg\right.$ indicates negative values of $\left.\mathrm{b} \widehat{c v_{5}}\right)$.

\begin{tabular}{cccccccccccc}
\hline \multicolumn{9}{c}{ Price Development } \\
\hline $\mathrm{Com}$ & $\mathrm{PDI}_{5}$ & $R^{2}$ & $\mathrm{Com}$ & $\mathrm{PDI}_{5}$ & $R^{2}$ & $\mathrm{Com}$ & $C V_{5}$ & $R^{2}$ & $\mathrm{Com}$ & $C V_{5}$ & $R^{2}$ \\
\hline $\mathrm{Ag}$ & 1.144 & $49.6 \%$ & $\mathrm{Mn}$ & 1.695 & $50.5 \%$ & $\mathrm{Ag}$ & 0.351 & $65.5 \%$ & $\mathrm{Mn}$ & 0.259 & $12.7 \%$ \\
$\mathrm{Al}$ & 1.057 & $16.0 \%$ & $\mathrm{Mo}$ & 1.777 & $16.1 \%$ & $\mathrm{Al}$ & 0.134 & $65.7 \%$ & $\mathrm{Mo}$ & 0.874 & $26.8 \%$ \\
$\mathrm{As}$ & 0.793 & $60.8 \%$ & $\mathrm{Na}$ & 1.305 & $56.9 \%$ & $\mathrm{As}$ & 0.196 & $41.9 \%$ & $\mathrm{Na}$ & 0.299 & $53.3 \%$ \\
$\mathrm{Au}$ & 0.495 & $50.4 \%$ & $\mathrm{Ni}$ & 1.377 & $12.3 \%$ & $\mathrm{Au}$ & $\neg$ & $\neg$ & $\mathrm{Ni}$ & 0.430 & $26.4 \%$ \\
$\mathrm{~B}$ & 0.848 & $71.1 \%$ & $\mathrm{P}$ & 1.344 & $22.9 \%$ & $\mathrm{~B}$ & $\neg$ & $\neg$ & $\mathrm{P}$ & 0.305 & $30.4 \%$ \\
$\mathrm{Be}$ & 0.527 & $40.6 \%$ & $\mathrm{~Pb}$ & 1.227 & $36.9 \%$ & $\mathrm{Be}$ & 0.359 & $6.5 \%$ & $\mathrm{~Pb}$ & 0.352 & $53.6 \%$ \\
$\mathrm{Bi}$ & 2.320 & $15.8 \%$ & $\mathrm{Pd}$ & 0.281 & $39.0 \%$ & $\mathrm{Bi}$ & 0.867 & $24.7 \%$ & $\mathrm{Pd}$ & 0.384 & $41.3 \%$ \\
$\mathrm{Br}$ & 1.006 & $7.5 \%$ & $\mathrm{Pt}$ & 0.163 & $26.5 \%$ & $\mathrm{Br}$ & 0.085 & $18.9 \%$ & $\mathrm{Pt}$ & $\neg$ & $\neg$ \\
$\mathrm{Cd}$ & 1.926 & $17.4 \%$ & $\mathrm{Re}$ & & & $\mathrm{Cd}$ & 1.005 & $57.8 \%$ & $\mathrm{Re}$ & 0.169 & $65.9 \%$ \\
$\mathrm{Co}$ & 1.454 & $35.8 \%$ & $\mathrm{Rh}$ & 5.578 & $37.7 \%$ & $\mathrm{Co}$ & 0.363 & $48.0 \%$ & $\mathrm{Rh}$ & 0.655 & $38.8 \%$ \\
$\mathrm{Cr}$ & 1.104 & $19.9 \%$ & $\mathrm{~S}$ & 1.306 & $23.7 \%$ & $\mathrm{Cr}$ & 0.321 & $25.7 \%$ & $\mathrm{~S}$ & 0.959 & $47.5 \%$ \\
$\mathrm{Cu}$ & 1.996 & $65.5 \%$ & $\mathrm{Sb}$ & 1.197 & $6.2 \%$ & $\mathrm{Cu}$ & 0.487 & $69.1 \%$ & $\mathrm{Sb}$ & 0.299 & $14.7 \%$ \\
$\mathrm{Fe}$ & 2.266 & $58.8 \%$ & $\mathrm{Si}$ & 1.022 & $24.0 \%$ & $\mathrm{Fe}$ & 0.437 & $26.5 \%$ & $\mathrm{Si}$ & 0.216 & $31.9 \%$ \\
$\mathrm{Ga}$ & 0.937 & $11.5 \%$ & $\mathrm{Sn}$ & 1.076 & $54.3 \%$ & $\mathrm{Ga}$ & & & $\mathrm{Sn}$ & 0.248 & $40.5 \%$ \\
$\mathrm{Ge}$ & 0.936 & $19.5 \%$ & $\mathrm{Sr}$ & 0.272 & $46.1 \%$ & $\mathrm{Ge}$ & 0.235 & $44.1 \%$ & $\mathrm{Sr}$ & 0.184 & $15.1 \%$ \\
$\mathrm{Hg}$ & 1.739 & $45.8 \%$ & $\mathrm{Ta}$ & 1.052 & $27.0 \%$ & $\mathrm{Hg}$ & 0.332 & $29.6 \%$ & $\mathrm{Ta}$ & 0.496 & $13.2 \%$ \\
$\mathrm{I}$ & 1.149 & $16.3 \%$ & $\mathrm{Ti}$ & 1.033 & $42.4 \%$ & $\mathrm{I}$ & 0.258 & $17.7 \%$ & $\mathrm{Ti}$ & 0.519 & $27.4 \%$ \\
$\mathrm{In}$ & 1.897 & $13.0 \%$ & $\mathrm{~V}$ & 1.718 & $17.2 \%$ & $\mathrm{In}$ & 0.431 & $33.0 \%$ & $\mathrm{~V}$ & 0.752 & $60.5 \%$ \\
$\mathrm{~K}$ & 1.160 & $30.9 \%$ & $\mathrm{~W}$ & 1.362 & $36.9 \%$ & $\mathrm{~K}$ & 0.223 & $19.4 \%$ & $\mathrm{~W}$ & 0.380 & $14.1 \%$ \\
$\mathrm{Li}$ & 1.074 & $13.1 \%$ & $\mathrm{Zn}$ & 2.101 & $33.8 \%$ & $\mathrm{Li}$ & 0.624 & $24.0 \%$ & $\mathrm{Zn}$ & 0.958 & $55.3 \%$ \\
$\mathrm{Mg}$ & 1.374 & $56.7 \%$ & $\mathrm{Zr}$ & 0.998 & $7.1 \%$ & $\mathrm{Mg}$ & 0.184 & $39.7 \%$ & $\mathrm{Zr}$ & 0.091 & $4.5 \%$ \\
\hline & & & & & & & & & & &
\end{tabular}

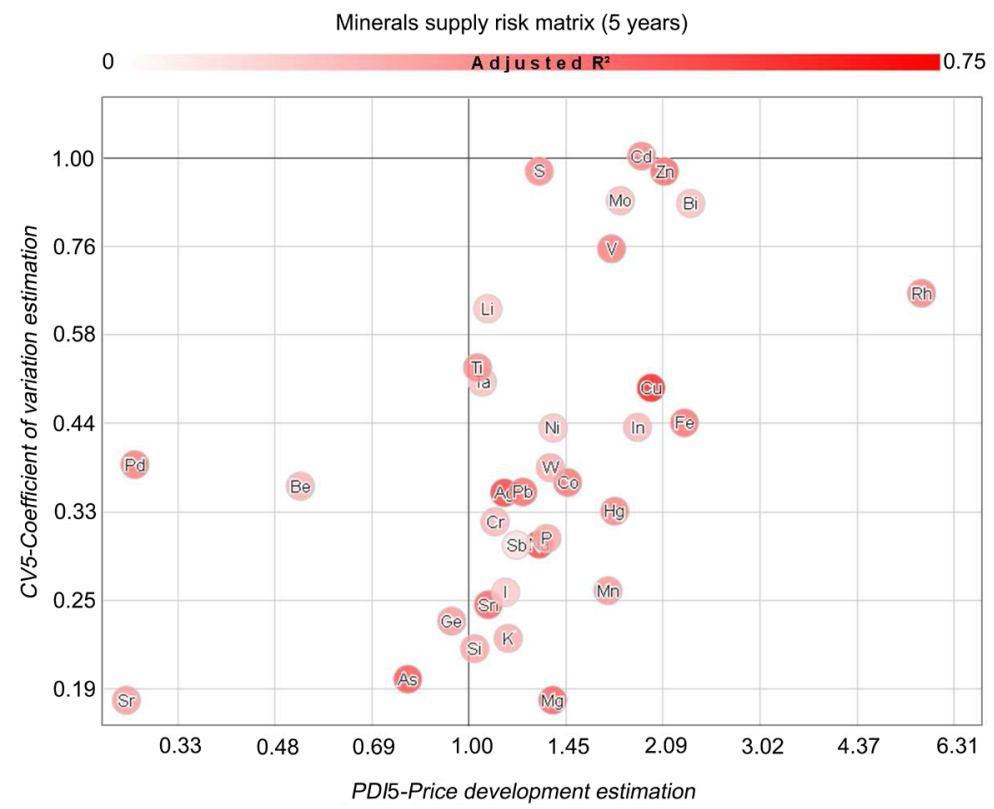

Figure 4. Supply risk matrix - representing future price trend and volatility predictions for planning horizon of five years from 2010. 
dies, listed in Figure 1, by implementing a risk matrix. The two logarithmic scaled axes are price development and future volatility. At first, looking at the overall picture of all materials, we can observe a correlation between predicted price development and volatility. The stronger the future price increases the more the future volatility of materials seems to rise for the time span of five years. The so called inverse-leverage-effect, also known as inventory effect, is a commodity specific phenomenon which has been under scientific study for some years now [32]-[34]. Accordingly, price increases cause way more volatility than negative price shocks. In order to explain that, researchers often refer to the theory of storage. Price increases potentially indicate a deterioration of the commodity inventories and thus signal an increasing probability of commodity stock-out. Besides, this explanation is consistent with the used definition of supply risk and hence confirms the use of price development as indicator for supply risk. Considering the individual results for each raw material and respective indicator, it is important to notice that these values represent estimates of price development, discounted by world inflation of $4.9 \%$ and calculated from the base period of 2010 . Thus, the time span from 2010 up to now is already included by these five year estimations. At a broad level, the group of bismuth, cadmium, rhenium and zinc shows the highest values, whereas arsenic, beryllium and strontium, by contrast, offer the lowest values for both, price trend and future volatility. Next, a selection of commodities is exemplary presented in order to give an idea of the concrete results. For instance, in the case of molybdenum we observe a high price increase over the next five years of 1.77 and also a very high coefficient of variation with 0.87 . To illustrate this result, a value of 1.0 for $\widehat{c v}_{t}$ implicates that average fluctuation of prices for the respective period is as high as the mean value. Thus, having high rates in both dimensions molybdenum hast to be stated as one of the rather highly critical materials regarding the overall supply risk. Reasons for this could be a tight supply and demand situation and the molybdenum co-production, since it is mainly produced as a co-product of copper mining. [35] shows that, due to the strong dependency on copper production, a change in the supply-demand-ratio can have a disproportionately large impact on the molybdenum price. This could be caused by the fact that getting more molybdenum as by-product from the current copper production requires costly adaptions to the production process. Our results substantiate these findings as the molybdenum price seems to depend strongly on the price development of copper, which has a potential price increase of 1.99 and normalized volatility of 0.48 . Therefore, a considerable supply risk can be assessed to copper. Due to the immense demand increases originating from the emerging markets, copper is one of the most-widely used metals required for a variety of applications in the energy and construction industry. Iron underlies a similar behavior: Having the highest consumption worldwide, supply risks may increase, referring to values of $\widehat{\mathrm{PDI}}_{5}$ with 2.27 and $\widehat{c v}_{5}$ with 0.44 . Rhodium is the element, which we assess as most critical. It shows an extreme value of estimated price trend of 5.57 and a potential volatility of 0.64. As an important component of automotive catalysts, it is often used in form of alloys. Although we expect high fluctuations as Rhodium is extremely rare in nature (with only 30 tons of yearly production volume), this estimations seem to be high. This effect may be caused by extreme price peaks in the years before 2010, when rhodium was being one of the most expensive metals at all. Nevertheless, these values indicate the relevance to supply risk in the stressed rhodium market.

Two rather uncritical elements, palladium and strontium, show the lowest level of price trend estimation. For both, price decreases are expected. Strontium also displays a low coefficient of variation of 0.18 as it is relatively frequent distributed in Earth's crust and immersed in seawater. In addition, demand is quite low, as it is only used for a small amount of applications: cathode ray tubes, pyrotechnics and in aluminum smelting. Despite the price bubble for palladium in and before the year 2010, which justifies potential price decrease, the concrete value of 0.28 appears to be very low. Especially, a technological innovation that offers more efficiency in processing carbon atoms with palladium-catalysed organic reactions, recognized by the Nobel Prize in chemistry, is not captured [36]. Furthermore, we observe two main clusters showing less to no real price increases, varying around the $\widehat{\mathrm{PDI}}_{5}$ threshold of 1.0. The first cluster to which decision makers should put more attention includes materials that show high volatility potential, e.g. lithium, sulfur, tantalum or titanium. The other less risky cluster contains, e.g. aluminium, bromine, silicon or zircon.

In summary, these results illustrate the great differences in behavior, characteristics and supply risk patterns of raw materials. For the group of bismuth, cadmium, rhenium and zinc, we except the most critical development of supply risk within the time span of 2011 to 2015. After presenting a substantial set of results of indicator weightings, model calibrations and assessment of criticality's supply risks dimension, we now continue with the results of the evaluation procedures. 


\subsection{Evaluation Results}

To test the robustness of the multiple regression models an out-of-sample test for the past five years was conducted, see section. The deviations from the estimated values of $\widehat{\mathrm{PDI}}_{t}$ and $\widehat{c v}_{t}$, once calculated on the basis of the complete $c d s$ and a once of a reduced dataset $r d s$, are compared to the actual values actual in 2006 to 2010. Furthermore, we compare the estimates of $r d s$ and $r d s$ with each other. The aggregated results are listed in Table 11.

On average, the price increase estimator models perform better and seem to be more robust as the models for future volatility. Although the $\widehat{c v_{t}}$-values show more significance and higher values of $R^{2}$ than the multivariate models of $\widehat{\mathrm{PDI}}_{t}$, see Table 7, the respective models here show higher deviations in comparison to the normal dataset as well as to the actual values. This effect can be explained by a larger range of characteristics of the coefficient of variation samples. The volatility models therefore can better explain these deflections but lose precision due to larger spans. Considering estimator's average relative deviation between the reduced and the normal model, we obtain low, but continuous underestimation throughout all supply risk estimators and periods. This is reasonable as the reduced models calibrations do not cover the massive price increases which were emerging in the first decade of the new millennium. For $\widehat{\mathrm{PDI}}_{1.3}$ in the same setting we observe absolute deviations of less than $5 \%$ that confirm the very good robustness of these models. $\widehat{\mathrm{PDI}}_{4,5}$ with $15.1 \%$ and $17.2 \%$ deviate by a greater amount, as they include the main years of the global financial crisis (2007-2012). The absolute deviations of $\widehat{c v} v_{1.5}$-estimators all vary close to their mean of $25.6 \%$. The best robustness of our estimators, comparing $r d s$ with $c d s$, we observe for $\widehat{\mathrm{PDI}}_{2} \quad$ a $-0.6 \%$ relative and a $4.4 \%$ absolute deviation. This means, that these estimates, even though calculated on $r d s$, do not vary much from the ones caculated by $c d s$. To return to the estimators $\widehat{\mathrm{PDI}}_{5}$ and $\widehat{c v}_{5}$ presented above, both show proper robustness and prediction quality. To illustrate, we with our price development estimator $\widehat{\mathrm{PDI}}_{5}$ underestimate real price trend by $3.9 \%(A R D)$ and miss actual development in average by $23 \%(A A D)$. For $\widehat{c v_{5}}$ we obtain slightly weaker values for of $4.4 \%(A R D)$ and $41.6 \%(A A D)$.

Next, looking at the overall picture, regarding deviations from calculated estimators to actual values of price development and future volatility, the same picture prevails: the $\widehat{\mathrm{PDI}}_{t}$ seem to perform better than the $\widehat{c v_{t}}$. While comparing the estimated price increases and volatilities of $c d s$ with the real values actual, it is noticeable that in most cases except the $\widehat{\mathrm{PDI}}_{4,5}$ and the $\widehat{c v}_{1,2}$, we overestimate the real developments on a relatively low level. This is, regarding the risk aversion of many decision makers, the better case than underestimating potential supply risks. Besides that, it is strikingly obvious that the approach is not working for the estimators $\widehat{c v}_{1,2}$, as average absolute estimator deviations of $171 \%$ and $187 \%$ of $c d s$ and red to actual values are not accepaptable at all. The still moderate values for average absolute deviations for $\widehat{c v_{3.5}}$ are caused by great differencs in prediction quality among the examined materials, which also show the low values of the average relative deviation within these three cases. Thus, before use, basically the individual prediction quality of each specific resource model has to be taken into account. In general, we observe that $c d s$ estimates compared to the actual

Table 11. Overview of the results of the out-of-sample test-relative and absolute deviations from price increase and volatility estimators (Relative (ARD) and absolute deviations (AAD) from price increase and volatility estimators $\widehat{\mathrm{PDI}}_{t}$ and coefficient of variation $\mathrm{b} \widehat{c v_{t}}$ based on a reduced dataset $(r d s)$ are compared to the ones calculated from the full dataset and to the actual values, as well as estimators calculated from the full dataset are compared to actual data).

\begin{tabular}{|c|c|c|c|c|c|c|}
\hline & \multicolumn{2}{|c|}{$r d s / c d s$} & \multicolumn{2}{|c|}{ rds/actual } & \multicolumn{2}{|c|}{$c d s /$ actual } \\
\hline & ARD & AAD & ARD & AAD & ARD & AAD \\
\hline $\mathrm{PDI}_{1}$ & $-2.1 \%$ & $4.4 \%$ & $2.9 \%$ & $13.9 \%$ & $9.9 \%$ & $19.2 \%$ \\
\hline $\mathrm{PDI}_{2}$ & $-0.6 \%$ & $4.3 \%$ & $5.8 \%$ & $25.3 \%$ & $6.4 \%$ & $24.1 \%$ \\
\hline $\mathrm{PDI}_{3}$ & $-4.0 \%$ & $6.9 \%$ & $-2.3 \%$ & $25.6 \%$ & $1.1 \%$ & $22.3 \%$ \\
\hline $\mathrm{PDI}_{4}$ & $-9.7 \%$ & $15.1 \%$ & $-9.3 \%$ & $33.2 \%$ & $-2.2 \%$ & $23.2 \%$ \\
\hline $\mathrm{PDI}_{5}$ & $-15.6 \%$ & $17.2 \%$ & $-18.6 \%$ & $31.5 \%$ & $-3.9 \%$ & $23.6 \%$ \\
\hline$C V_{1}$ & $-4.4 \%$ & $27.1 \%$ & $130.7 \%$ & $187.3 \%$ & $130.6 \%$ & $171.9 \%$ \\
\hline$C V_{2}$ & $-7.5 \%$ & $20.4 \%$ & $26.4 \%$ & $70.0 \%$ & $47.3 \%$ & $79.8 \%$ \\
\hline$C V_{3}$ & $-11.9 \%$ & $25.4 \%$ & $7.7 \%$ & $62.7 \%$ & $19.8 \%$ & $55.0 \%$ \\
\hline $\mathrm{CV}_{4}$ & $-15.6 \%$ & $26.1 \%$ & $-3.1 \%$ & $60.9 \%$ & $8.6 \%$ & $44.6 \%$ \\
\hline $\mathrm{CV}_{5}$ & $-18.7 \%$ & $29.1 \%$ & $-7.8 \%$ & $60.7 \%$ & $4.4 \%$ & $41.6 \%$ \\
\hline
\end{tabular}


values perform slightly better than the ones of $r d s$. This expected result is reasonable as the estimates calculated on $c d s$ are supposed to include more information. Hence, from an overall perspective, the out-of-sample test confirms the robustness of our multiple regression model and proves the prediction quality for most of the examined estimators and planning horizons. All in all we can conclude from these simulations, that the developed supply risk estimators offer a substantial information gain when making decisions under uncertainty in raw material storage planning.

\section{Discussion}

In this section, we will discuss the results of our study. Besides interpretation of principal findings, the significance and contribution to existing knowledge and practice is presented. Finally, this chapter summarizes key findings, followed by the conclusion of this work.

Examining the supply risk dimension of raw materials' criticality, our results show that future price trend and volatility are significantly influenced by a number of current material specific and general economic indicators, such as country concentration, secondary production or interest rate. Thus, the supply risk determinants price development and future fluctuations are not just random walks, but in many cases are driven by fundamental factors of today. Besides, all quantitative indicators generally justify their utilization assessing future supply risk, since they show considerable significance and explain dispersion for a variety of different materials and time spans. The respective sets of relevant factors as well as their timely impacts vary substantially among the diverse elements. Thereby for each driving factor in the multivariate models we exactly determine the weighting and importance. By the means of a material planning simulation and an out-of-sample test, two procedures were applied to evaluate the model. We could prove robustness, reliability for most cases. In particular the practical suitability of the presented method can be stated, as for the majority of resources we observed excellent performance using the supply risk estimators as decision criterion for material planning.

\subsection{Interpretation of Findings}

As expected, there are great differences regarding the explanatory power and prediction quality of the supply risk assessment models for specific elements, as in detail described above. Moreover, it is noticeable that materials such as aluminum, copper, gold, iron, phosphorus, potassium, silver or vanadium which have a high trading volume and where demand is mostly driven by a few main components ensure a better functioning than their counterparts. These are antimony, gallium, indium, lithium and tantalum. They are less traded and face a more heterogeneous demand structure. This suggests that future supply risks underly structural breaks, such as the unexpected use in new technologies, which can hardly be reflected by a statistical framework.

According to these results it is important to emphasize, when assessing supply risk and thus raw material criticality, which each element has to be considered individually according to its resource specific characteristics. Before practically applying the presented method, it is indispensable to form an accurate picture of the specific results of each element, since performance of the models, usability and robustness are varying and are highly material dependent.

\subsection{Implications in Context of Literature}

With regard to literature and related work, this paper identifies four central issues and makes a number of significant contributions to existing knowledge. First, based on our results we think that from an empirical point of view arbitrarily chosen percentages for criticality indexes are not justified. Secondly, we are convinced that generic weights assigned to all materials are highly error-prone, as different materials show significantly different correlations with each indicator. This thesis is also supported by [10] or [37], who figured out that most metal price volatility is commodity-specific. Thirdly, a fixed selection of indicators is inadequate, as some indicators show a high correlation with the supply or criticality aggregate of some raw materials, but no correlation at all with the criticality construct of others. From our analysis country concentration crystallizes out as one of the most important indicators. Therefore in general, criticality indexes should use a specific and empirically determined weighting for every specific metal based on a specific set of indicators. This result is, in contrast to current methods, applied by, for instance, the Department of Energy [8], the [5] or the IZT [17]. Also, the main economic indicators representing demand are not taken into account by current studies. However, GDP, interest 
rate as well as inflation, have turned out to be quite good indicators for the development of supply risks, thus, could also influence criticality. Though only for a few materials data is available, futures confirm the suggestion to be a more than reasonable commodity market indicator, as reflecting market expectations. Also [9] with the latest work improve criticality measurement to a large extent but do not consider the named issues. Criticality assessments therefore should explicitly address future supply risk, include main economic market indicators and be revised with individual models and weighting factors for each element in order to come to more reliable conclusions. Finally, regarding volatility, our results demonstrate the inverse leverage or inventory effect, which has been postulated by a number of studies, for instance [32]-[34].

\subsection{Practical Implications}

When we come to the implications for practice, addressing the management of raw materials, we recommend the inclusion of information from different perspectives into the process of decision-making. There are fundamental as well as deductive expert opinion based approaches, which are at least as important and need to be considered. This study, in contrast, sheds some more light on empirical supply criticality assessment. Despite the alternate approaches our study provides some features, which are worth regarding. Compared to other works the presented methodology ensures a cardinal scale, which, given the correctness of data, enables extended possibilities in risk assessment as well as financial evaluation of commodity depending projects. In addition, the presented framework allows dynamic supply risk assessment from different points in time. The findings of this research are not only interesting in context of material planning. Another more concrete practical implication could be the use in exploration planning, thus future mine production volumes. Currently, producers are planning and calculating these volumes on actual price levels and expectations [38]. The use of the presented price development indicator possibly improves exploration planning and thus could contribute to decreasing likelihood of shortages caused by bad planning.

\subsection{Limitations}

While this study has produced interesting results and implications in a number of ways, it has, however, limitations that need to be acknowledged: As our model is purely quantitative and statistical, neither fundamental nor theoretic deductive, no qualitative effects can be observed beyond the quantitative data set. As already mentioned, due to the construction of both supply risk estimators, $\widehat{\mathrm{PDI}}$ and $\widehat{c v}$, autocorrelation in these two variables necessarily is present, more or less. However, by the application of the common measures for autocorrelation-correction, we would lose information that is essential for our study. Thus, regarding this aspect, there is still room for improvement, to avoid potential biases. Moreover, there could be additional significant impact factors not yet captured. Considering captured indicator figures, the data partially involves estimates as well as it may include data errors, hence, it has to be taken into account that supply risk estimations can be just as good as input data is. Furthermore, the data situation, especially for trace metals like indium or gallium is highly intransparent, and all data is often provided by a single source. Hence, even the extensive analyses we performed in this paper still never will be able to fully explain the development of commodity prices and fluctuations, since there is a number of factors influencing future supply risk and criticality, such as clashes, new technologies or natural disasters, that are hardly predictable from current driving factor constellations. Lastly, critically reviewing theory of efficient markets, which would claim that all known and predictable future risks are included in prices, there is some reason for doubt regarding efficient markets in this domain, especially when not traded on stock markets but over the counter.

\section{Conclusion}

Taken as a whole, in spite of the presented limitations, we hope that our results contribute to the enhancement of further research on measurement of criticality, as well as on the clarification of some frequently discussed questions, especially on how each indicator influences the supply risk for the respective raw materials. While the developed framework and the resulting values are certainly not a final result, we are convinced that it is now clear that fixed percentages over all raw materials are highly doubtful, that material and indicator specific weights offer a much more valid baseline for criticality indicators, that criticality assessments should explicitly focus on future, and that there is requirement for practical applicability. In summary, the findings of this paper are impor- 
tant as they help both a better support and extended research of raw materials' criticality. Most notably, this paper addresses four issues enhancing current approaches: a) outlining major lacks and gaps of current works; b) improvement of the methodological procedure of assessing supply risk dimension of criticality; c) enabling forecasts about future materials' price development and volatility; d) improving usability for industrial application which enables companies and politics to be aware and at least partly counteract upcoming critical market developments. Although this topic still yields a large number of further questions to be answered by future research, we hope that our approach can contribute to advanced understanding and application of measurement of raw materials' criticality.

\section{References}

[1] ICSG (2012) The World Copper Factbook 2012 International. The International Copper Study Group, Lisbon.

[2] National Research Council (2008) Minerals, Critical Minerals, and the USA Economy. The National Academies Press.

[3] Pfleger, P.K.L., Bardt, H. and Reller, A. (2009) Rohstoffsituation Bayern: Keine Zukunft ohne Rohstoffe. IW Consult, Munich.

[4] Achzet, B., Zepf, V., Meissner, S. and Reller, A. (2010) Strategies for a Responsible Handling of Metals and Their Resources. Chemie Ingenieur Technik, 82, 1913-1924.

[5] EC (European Commission) (2010) Critical Raw Materials for the EU. Report of the Ad-Hoc Working Group on Defining Critical Raw Materials. EC, Brussels.

[6] Rosenau-Tornow, D., Buchholz, P., Riemann, A. and Wagner, M. (2009) Assessing the Long-Term Supply Risks for Mineral Raw Materials-A Combined Evaluation of Past and Future Trends. Resources Policy, 34, 161-175. http://dx.doi.org/10.1016/j.resourpol.2009.07.001

[7] Erdmann, L. and Graedel, T.E. (2011) The Criticality of Non-Fuel Minerals: A Review of Major Approaches and Analyses. Environmental Science \& Technology, 45, 7620-7630. http://dx.doi.org/10.1021/es200563g

[8] Bauer, D., Diamond, D., Li, J., Sandalow, D., Telleen, P. and Wanner, B. (2010) Critical Materials Strategy. USA Department of Energy, Washington DC.

[9] Graedel, T.E., et al. (2012) Methodology of Metal Criticality Determination. Environmental Science \& Technology, 46, 1063-1070. http://dx.doi.org/10.1021/es203534z

[10] Gleich, B., Achzet, B., Mayer, H. and Rathgeber, A. (2013) An Empirical Approach to Determine Specific Weights of Driving Factors for the Price of Commodities? A Contribution to the Measurement of the Economic Scarcity of Minerals and Metals. Resources Policy, 38, 350-362. http://dx.doi.org/10.1016/j.resourpol.2013.03.011

[11] Smith, M. (2005) European Strategic Metals \& Industrial Minerals-Knowledge Gaps Risks \& Vulnerabilities. Gecko Environment.

[12] Behrendt, S., Scharp, M., Kahlenborn, W., Feil, M., Dereje, C., Bleischwitz, R. and Delzeit, R. (2007) Seltene Metalle -Maßnahmen und Konzepte zur Lösung des Problems konfliktverschärfender Rohstoffausbeutung am Beispiel Coltan. Umwelt Bundes Amt.

[13] Wouters, H. and Bol, D. (2009) Material Scarcity. Materials Innovation Institute.

[14] Massachusetts Institute of Technology (2010) Critical Elements for New Energy Technologies. MIT, Cambridge.

[15] Geological Survey of Finland (2010) Finland's Minerals Strategy. www.mineraalistrategia.fi

[16] Waeger, P., Lang, D., Bleischwitz, R., Hagelüken, C., Meissner, S., Reller, A. and Wittmer, D. (2010) Rare MetalsRaw Materials for Technologies of the Future. Swiss Academy of Engineering Sciences.

[17] Behrent, S., Erdman, L. and Feil, M. (2011) Kritische Rohstoffe für Deutschland-Identifikation aus Sicht deutscher Unternehmen wirtschaftlich bedeutsamer mineralischer Rohstoffe, deren Versorgungslage sich mittel-bis langfristig als kritisch erweisen könnte. KfW Bankengruppe.

[18] Duclos, S.J., Otto, J.P. and Konitzer, D.G. (2010) Design in an Era of Constrained Resources. Mechanical Engineering, 132, 36-40.

[19] Thomason, J.S., Atwell, R.J., Bajraktari, Y., Bell, J.P., Barnett, D.S., Karvonides, N.S., Niles, M.F. and Schwartz, E.L. (2008) From National Defense Stockpile (NDS) to Strategic Materials Security Program (SMSP): Evidence and Analytic Support. Institute for Defense Analyses (IDA), Alexandria, VA.

[20] Frondel, M., Grösche, P., Huchtemann, D., Oberheitmann, A., Petersand, J., Angerer, G., Buchholz, C.S., Röhling, S.P. and Wagner, M. (2007) Trends der Angebots- und Nachfragesituation bei mineralischen Rohstoffen. Rheinisch-Westfälisches Institut für Wirtschaftsforschung (RWI Essen), Fraunhofer-Institut für System- und Innovationsforschung (ISI), Bundesanstalt für Geowissenschaften und Rohstoffe (BGR). 
[21] Tilton, J. (2002) On Borrowed Time? Assessing the Threat of Mineral Depletion. RFF Press Series, Resources for the Future, Washington DC.

[22] Tilton, J.E. (2009) Is Mineral Depletion a Threat to Sustainable Mining?

[23] Alonso, E., Gregory, J., Field, F. and Kirchain, R. (2008) Material Availability and the Supply Chain: Risks, Effects, and Responses. Environmental Science \& Technology, 19, 6649-6656.

[24] Chambers, M.J. and Bailey, R.E. (1996) A Theory of Commodity Price Fluctuations. Journal of Political Economy, 104, 924-957. http://dx.doi.org/10.1086/262047

[25] Svedberg, P. and Tilton, J.E. (2006) The Real, Real Price of Nonrenewable Resources: Copper 1870-2000. World Development, 34, 501-519. http://dx.doi.org/10.1016/j.worlddev.2005.07.018

[26] Hotelling, H. (1931) The Economics of Exhaustible Resources. Journal of Political Economy, 39, 137-175. http://dx.doi.org/10.1086/254195

[27] Krautkraemer, J.A. (1998) Nonrenewable Resource Scarcity. Journal of Economic Literature, 36, 2065-2107.

[28] Jarque, C.M. and Bera, A.K. (1980) Efficient Tests for Normality, Homoscedasticity and Serial Independence of Regression Residuals. Economics Letters, 6, 255-259. http://dx.doi.org/10.1016/0165-1765(80)90024-5

[29] Breusch, T.S. and Pagan, A.R. (1979) A Simple Test for Heteroscedasticity and Random Coefficient Variation. Econometrica, 47, 1287-1294. http://dx.doi.org/10.2307/1911963

[30] Savin, N.E. and White, K.J. (1977) The Durbin-Watson Test for Serial Correlation with Extreme Sample Sizes or Many Regressors. Econometric, 45, 1989-1996. http://dx.doi.org/10.2307/1914122

[31] Marquardt, D.W. (1970) Generalized Inverses, Ridge Regression, Biased Linear Estimation, and Nonlinear Estimation. Technometrics, 12, 591-612. http://dx.doi.org/10.2307/1267205

[32] Lien, D.H.D. (1987) The Inventory Effect in Commodity Futures Markets: An Empirical Study. Journal of Futures Markets, 7, 637-652. http://dx.doi.org/10.1002/fut.3990070604

[33] Pindyck, R.S. (2001) The Dynamics of Commodity Spot and Futures Markets: A Primer. The Energy Journal, 22, 130.

[34] Carpantier, J.F. and Samkharadze, B. (2012) The Asymmetric Commodity Inventory Effect on the Optimal Hedge Ratio. Journal of Futures Markets, 33, 1096-9934.

[35] Langhammer, D. (2010) An Empirical Analysis of Structural Forces in Refractory Metal Markets. Dissertation, Augsburg University, Augsburg.

[36] Croft, L. (2010) Nobel Prize 2010: Prestige for Palladium. Nature Chemistry, 2, 1009.

[37] Chen, M.-H. (2010) Understanding World Metals Prices-Returns, Volatility and Diversification. Resources Policy, 35, 127-140. http://dx.doi.org/10.1016/j.resourpol.2010.01.001

[38] Moon, C., Whateley, M. and Evans, A. (2006) Introduction to Mineral Exploration. John Wiley \& Sons, New York. 
Scientific Research Publishing (SCIRP) is one of the largest Open Access journal publishers. It is currently publishing more than 200 open access, online, peer-reviewed journals covering a wide range of academic disciplines. SCIRP serves the worldwide academic communities and contributes to the progress and application of science with its publication.

Other selected journals from SCIRP are listed as below. Submit your manuscript to us via either submit@scirp.org or Online Submission Portal.
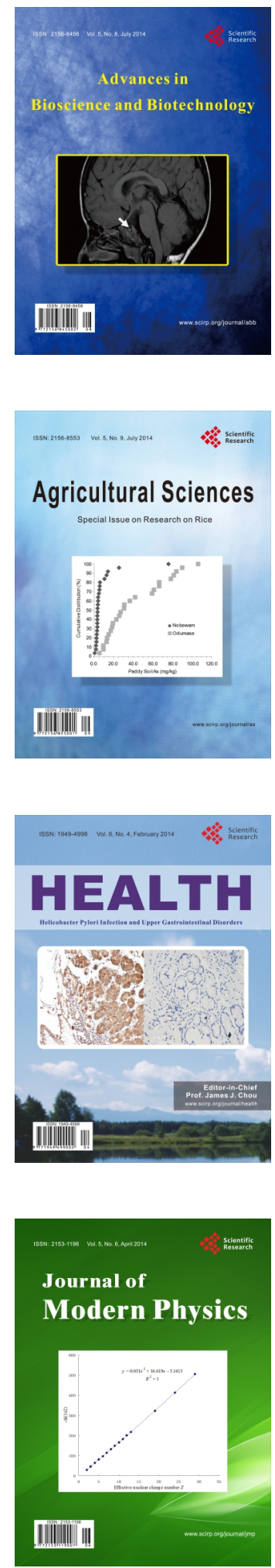
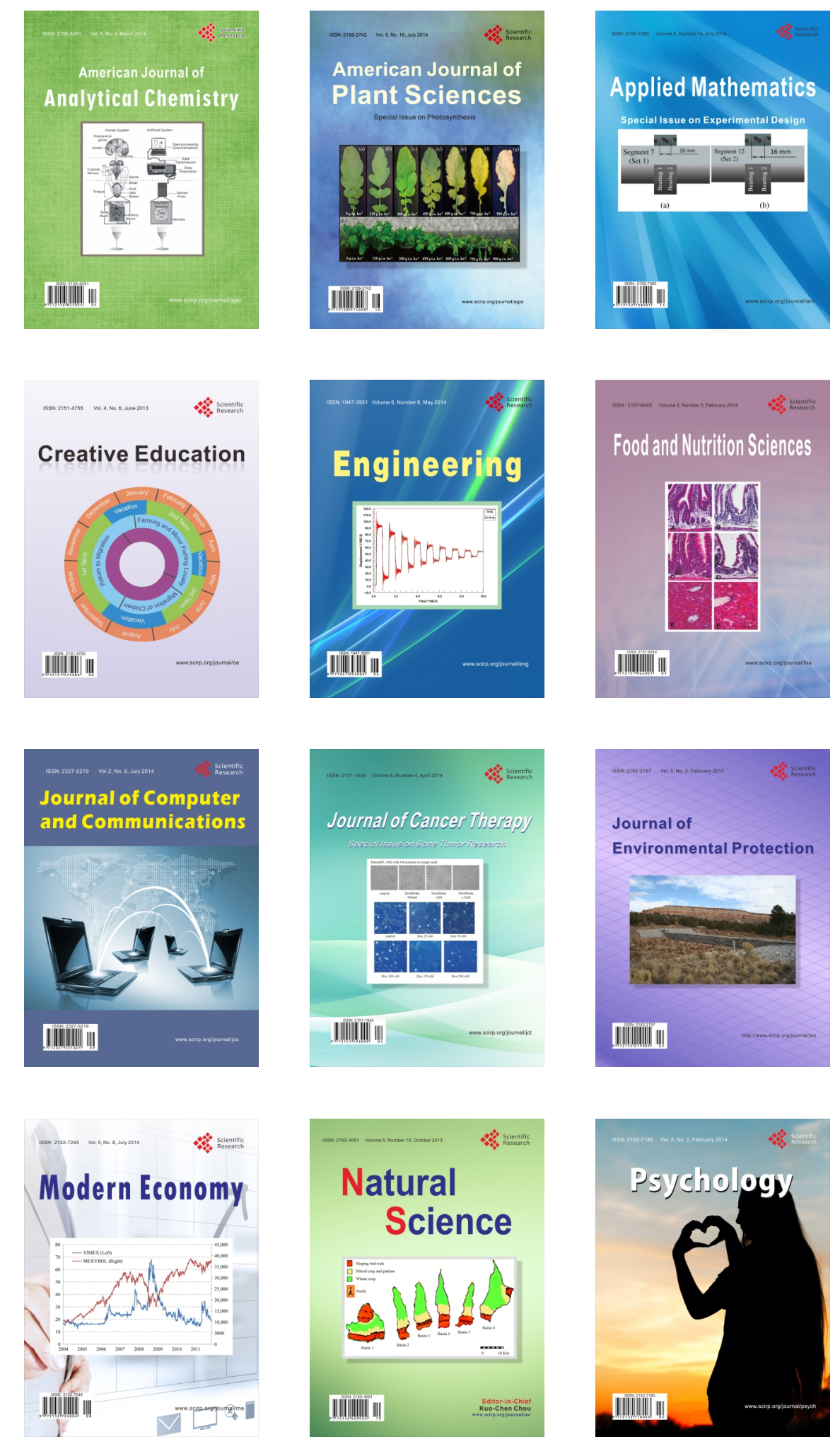